\title{
1 Material uncertainties vs joint structural detailing: relative effect on 2 the seismic fragility of reinforced concrete frames
}

6 Abstract

7 This paper investigates the relative effect of material properties and structural details in the joint panels on seismic fragility of

8 existing reinforced concrete (RC) frames. Five building classes with different structural details (particularly in the joint panels)

9 and material characteristics are defined according to different past design codes, for a three- and a six-storey archetype

10 geometry. Based on non-linear static or non-linear dynamic analysis procedures, results from the study show that the effect of

11 structural details on seismic fragility of the considered structures is negligible for damage states involving an essentially-elastic

12 behaviour. Conversely, this is much higher for the life-safety and near-collapse damage states, and it is considerably higher

13 than the one due to materials. Therefore, in the diagnosis phase, higher emphasis should be given to on-site investigations on

14 the actual reinforcement content/layout rather than to invasive material testing. The uncertainty related to the structural details

15 described herein is practically related to the exterior, rather than interior, joint panels. Cover removal for one of those joints

16 could potentially eliminate this specific uncertainty. As a practical action, a good practice for the in-situ testing of RC frames

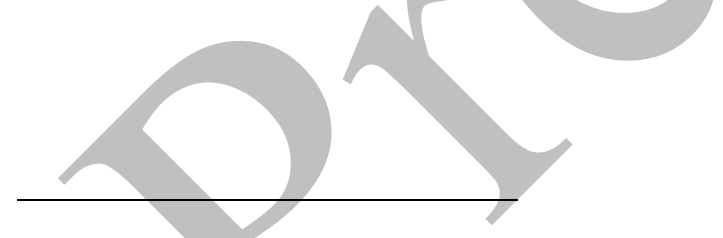

${ }^{1}$ Marie Curie Senior Research Fellow. Institute for Risk and Disaster Reduction, University College London, London, United Kingdom

${ }^{2}$ Associate Professor. Department of Civil, Environmental and Geomatic Engineering, University College London, London, United Kingdom

${ }^{3}$ Associate Professor. Scuola Universitaria Superiore IUSS, Pavia, Italy

${ }^{4}$ Full Professor. Dipartimento di Ingegneria Strutturale e Geotecnica, Università di Roma "La Sapienza", Rome, Italy

${ }^{5}$ Adjunct Professor. Department of Civil and Natural Resources Engineering, University of Canterbury, Christchurch, New Zealand 
17 should involve the cover removal of at least one exterior joint panel, regardless of the required target "level of knowledge" of

18 the existing structure.

\section{1. INTRODUCTION AND MOTIVATIONS}

20 In the seismic performance assessment of existing structures, if detailed structural drawings/reports are not available,

21 practitioners usually rely on simulated design to derive an estimate of relevant quantities for the assessment, e.g. amount of

22 reinforcement and material properties. This is done according to the relevant code-of-practice, consistently with the year of construction/retrofit of the structure under investigation. In addition, in-situ (diagnosis) testing can be performed to learn the actual quantities and confirm/enhance the assumptions made in the simulated design. This allows an analysis to somehow reduce the epistemic uncertainties related to material properties and structural details that can strongly influence the seismic performance of existing buildings. For reinforced concrete (RC) frames, such uncertainties can affect the hierarchy of strength at both member and beam-column joint levels, which in turn can affect the global plastic mechanism, the force/displacement capacity of the structure and/or its seismic fragility/vulnerability.

29 International codes/guidelines (e.g. Eurocode 8, European Committee for Standardisation (CEN), 2005; ASCE 41-17, 30 American Society of Civil Engineers (ASCE), 2017; NZSEE 2017, New Zealand Society for Earthquake Engineering 31 (NZSEE), 2017) suggest that structural details should be carefully checked, although detailed investigation/testing are not strictly required. In such documents, provisions related to in-situ testing tend to focus on materials rather than structural details, especially when "low levels" of knowledge are selected by the practitioner. This typically reflects in prescribing/suggesting a minimum number of concrete cores and rebar tensile tests. Such tests also enable the identification of critically-low material characteristics which may suggest immediate demolition of the investigated structure. Moreover, simulated design is less straightforward in relation to structural detail layouts, for which typical construction practices may govern the design, in absence of strict provisions in (older) codes. Among many typologies, structural details in joint panels are especially important

38 for the seismic response of RC frames, as confirmed by experimental and numerical evidence, as well as post-earthquake field 39 investigations (e.g. Pampanin et al. 2003; De Luca et al. 2018, among others). In the practice, greater confidence is typically 
gained on the material mechanical properties, rather than on the layout of structural details, leading to potentially-higher

41

uncertainties on the expected structural response and seismic performance.

Various literature studies provided insights on the effect of different model parameters on the fragility estimates for RC frames. The most commonly-considered parameters are: concrete, steel and masonry infill properties; parameters of empirical capacity models for members; elastic damping; seismic mass. Consensus is established in asserting that aleatory uncertainty due to record-to-record (R2R) ground-motion variability is more significant than epistemic (modelling) uncertainty due to model parameters (e.g. Kwon and Elnashai 2006; Celik and Ellingwood 2010). In a recent opinion paper, Bradley (2013) claims that this may not be true if higher-level uncertainties related to the model selection (rather than the parameters of a particular model) are also considered. Many studies (e.g. Celik and Ellingwood 2010; Celarec and Ricci 2012; Celarec et al. 2012; Kosič et al. 2012; Yu et al. 2016; Franchin et al. 2018) state that uncertainty due to model parameters have a greater effect for increased level of damage - or limit - states (DSs), but including them should have only a minor impact on seismic fragility analysis. By extending this concept, Dolšek (2009); Liel et al. (2009); and Gokkaya et al. (2016) state that modelling uncertainties related to the capacity models implemented in the numerical representation of the structure under investigation can significantlyincrease the logarithmic standard deviation (dispersion) of collapse fragility and slightly-reduce its median, if collapse is intended as the exceedance of a particularly-high drift threshold (e.g. 10\%) or a dynamic instability in the non-linear analyses (failed convergence).

Although the significance of structural details is generally pointed out in uncertainty-quantification studies (e.g. Kosič et al. 2012), very few studies explicitly considered the variation of such details. For example, parameters such as bar diameter, anchorage, splice length or concrete cover were considered in Jalayer et al. 2010. To the authors' knowledge, no previous study has investigated the influence of structural details in the joint panels, although some (e.g Celik and Ellingwood 2010; O'Reilly and Sullivan 2018) have considered the uncertainty of their non-linear capacity parameters (shear strain and force) within a single structural detail configuration.

62 This paper focuses on quantifying the relative effect of material uncertainties and structural details with specific focus on the 3 joint panels - as it can directly influence the hierarchy of strength, and thus both local and global mechanism of the frame sub- 
assemblies - on the seismic fragility of existing $\mathrm{RC}$ frames. The aim is to provide a more mechanics-based rationale to drive in-situ testing for RC frames, suggesting improvements in assessment and retrofit good-practice, guidelines and/or code provisions. For this reason, the variables considered in this study are selected according to the typical information (possibly) obtained from in-situ testing, i.e. the strength of concrete/steel and the typology of structural details in the joint panels (for a given modelling approach). Considering the modelling uncertainties related to different models for the joint panels (for a given structural detail) should be the focus of further research and it is deemed out of scope herein, since the objective of this paper is to highlight the effect of different joint structural details on the potential outcome of a seismic performance assessment. It is worth mentioning that degradation of the materials (e.g. ageing of concrete, corrosion of steel) is not considered in this study, although this is clearly an important aspect worth of investigation. Moreover, lap-splice failure is not considered in this work (the results are valid in the hypothesis that the splice length of the bars, smooth or deformed, is sufficient). Although the beam lap-splice failure may be frequent in old buildings, this mechanism would prevent the shear failure in the joint panels.

In this paper, different Italian design codes ranging from 1939 to 2008 are selected to define five building classes. The proposed methodology - based on sensitivity analysis - and the (at least qualitative and relative) obtained results are however general. Indeed, a tentative mapping of the same details to those from major international codes (New Zealand, USA) is provided. Each class is characterised by different structural details, with more emphasis on exterior joint panels. For each class, two geometrical configurations are chosen: three- and six-storey frames with three bays. For each of these ten configurations, random variations of the concrete cylindrical compressive strength and steel yield stress are sampled according to a ninefactorial design of experiment (DoE). Fragility curves are defined for each sampled frame, using numerical pushover analysis and the analytical method SLaMA (Simple Lateral Mechanism Analysis, New Zealand Society for Earthquake Engineering (NZSEE) 2017; Pampanin 2017; Gentile et al. 2019b), both coupled with the capacity spectrum method (CSM, Freeman 2004) and using natural (i.e., recorded) ground motions. Such methods are validated by comparison with refined non-linear timehistory analyses (NLTHA) adopting average values of the material properties.

6 The methodology of the sensitivity analysis is described in Section 2, together with the description of the RC frame case studies, the sampled values for materials and structural detail properties, the adopted non-linear analysis methods and the input 

ground motions. Section 3 shows the results of several non-linear analyses (considering 810 numerical models) carried out and describes the relative influence of materials and joint structural details on seismic fragility. Conclusions are provided in Section 4, including possible implications on codes/guidelines/good practice provisions related to in-situ testing.

\section{METHODOLOGY}

\subsection{Selected case-study frames}

The archetype frames are defined starting from a common plan geometry typical of residential buildings (Figure 1a), and considering three- and six-storey alternatives (Figure 1b). The central longitudinal frames of such configurations are selected for this study. For each frame geometry, five classes are selected with respect to different design approaches (e.g. allowable stresses vs limit states; or gravity-load only vs seismic design), different structural details and material properties. The considered configurations reflect the evolution of the main international standards for structural/seismic design. The evolution of the Italian structural codes (Table 1) is herein used as a reference to define the selected classes, and therefore each of them can be considered representative of a different time period. To quantify gravity loads and seismic masses, a concrete specific weight equal to $25 \mathrm{kN} / \mathrm{m}^{3}$ is considered, along with a superimposed dead load equal to $3 \mathrm{kN} / \mathrm{m}^{2}$, and a (factored) live load equal to $0.9 \mathrm{kN} / \mathrm{m}^{2}$. The axial load on the columns is calculated based on tributary areas. It is worth mentioning that gravity loadinduced bending moments are neglected in the analyses. Introducing them would likely produce a reduction of the median fragility of each case-study structure, with respect to the ones calculated in this paper. In fact, for very low realisations of the material properties (Section 2.2), the flexural capacity of some members may be exceeded due to gravity loads only. This would theoretically imply fragility curves with zero median and dispersion. In turn, this would considerably affect the calculation of the expected-value fragility curves described in Section 2.5. Considering that this paper focuses only on relative fragility results, it is decided to simplify the calculations by neglecting gravity-induced bending moments to avoid the above issue. More research effort is needed to quantify the shift of the median fragility of older design layouts due to gravity-induced bending moments. 
a) plan view

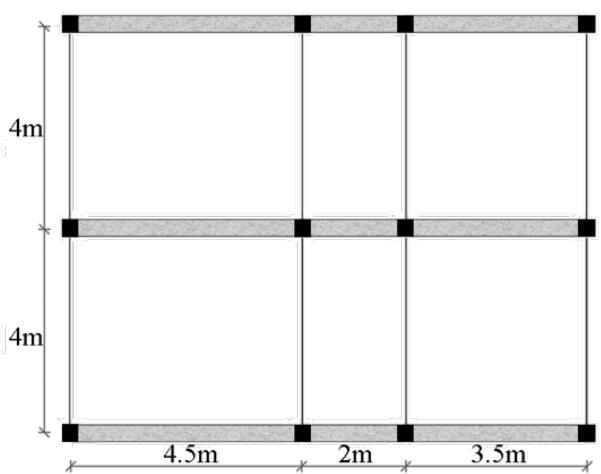

b) side views

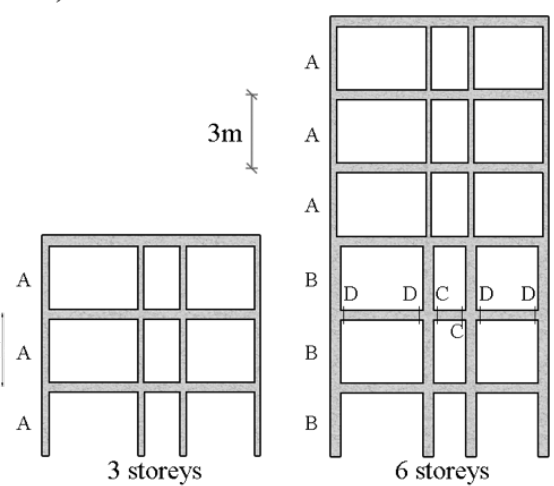

c) typical cross-sections (classes 1-4)

111 Figure 1. Archetype frames: (a) plan view; (b) longitudinal frame elevation; (c) typical RC members for classes 1-4. The

112 reinforcement notation refers to the number of bars and their diameter in millimetres (e.g. $4 \phi 18$ refers to four $18 \mathrm{~mm}$-diameter bars).

113 Superior and inferior bars are separated by a plus sign in the notation.

114 Table 1. Evolution of the main Italian structural codes.

\begin{tabular}{|c|c|c|c|c|c|}
\hline 1939 & 1976 & 1996 & 2003 & 2008 & 2018 \\
\hline \multirow{2}{*}{ RD 2229/39 } & \multirow{2}{*}{ L n.176 26/04/76 } & & DM 16/01/96* & \multirow{2}{*}{ DM 14/01/2008 } & \multirow{2}{*}{ DM 17/01/2018 } \\
\hline & & & OPCM n. 3274 20/03/2003** & & \\
\hline \multicolumn{2}{|c|}{ Classes 1,2,3: pre-1976 } & & Class 4: 1977-2007 & \multicolumn{2}{|c|}{ Class 5: post-2008 } \\
\hline
\end{tabular}

$115 *$ Limit state design only suggested; **Recommendations/guidelines not become mandatory/code as originally intended.

116 Classes 1, 2 and 3 refer to pre-1976 buildings, designed according to the "Regio Decreto 2229" issued in 1939 (Consiglio dei

117 Ministri 1939). Structural members are designed only considering gravity loads and adopting the allowable stresses approach

118 for the safety checks. The longitudinal reinforcement ratio of the columns ranges between $0.63 \%$ and $1.13 \%(0.27 \%-0.37 \%$

119 for the transverse one), while their axial load ratio is in the range $3 \%-20 \%$. The longitudinal reinforcement ratio of the beams

120 ranges between $0.81 \%$ and $0.98 \%$ (the transverse one is approximately equal to $0.29 \%$ ). No lateral-load design is provided,

121 nor any consideration of capacity design in single members (e.g. flexure vs shear) or in beam-column joint connections (e.g.

122 strong column/weak beam). The three classes differ for the structural details considered in the exterior joint panels (shown in

123 Figure 2 and discussed below).

124 These classes may be approximately mapped to similar classes for a similar time period in both New Zealand and USA. In

125 particular, after the introduction of the American concrete institute ACI 318:1971 standard (ACI Committee 318 1971), the

126 design practice in USA was entirely based on ultimate limit state (ULS) design (although this was already introduced in an 

recommendations for strong column weak beam behaviour). Regarding the detailing of beam-column joint panels, the

129 ACI/ASCE committee 352 (1966) may be considered, which issued the first joint detailing recommendations in 1976 (Wight and Parra-Montesinos 2012). Since 1968, ULS design and capacity design principles were introduced in New Zealand in a code of practice document issued by the Ministry of Works (MOW 1968), while such principles became the norm in 1976 with the introduction of the loading standard NZS 4203:1976 (Standards association of New Zealand 1976), while the reference concrete standard was ACI 318:1971 (ACI Committee 318 1971).

Class 4 refers to the period 1977-2007. It was mandatory to consider wind loads after 1978 (Consiglio dei Ministri 1978), and this resulted in slightly bigger column sizes and higher amount of shear reinforcement. However, design seismic actions on structures within this period were highly heterogenous in both space and time (see for example Crowley et al. 2020). For some Italian regions, seismic loads were introduced according to a 1976 law (Consiglio dei Ministri 1976), and similar provisions were introduced over time for other regions. A minimum amount of lateral loads (approximately $15 \%$ of the total weight, with a linear profile along the height) is considered in the simulated design of this class, to consider a region with underestimated seismic actions. This resulted in a similar longitudinal reinforcement configuration with respect to classes 1-3, but higher transverse reinforcement. The longitudinal reinforcement ratio of the columns ranges between $0.63 \%$ and $1.13 \%(0.42 \%$ $0.58 \%$ for the transverse one), while their axial load ratio is in the range $3 \%-20 \%$. The longitudinal reinforcement ratio of the beams ranges between $0.81 \%$ and $0.98 \%$ (the transverse one is approximately equal to $0.29 \%$ ). No joint stirrups are included. Allowable stresses are still the adopted design approach, with no capacity design considerations. Although in this period the seismic code promoted the protection of the joint panels, no explicit provision for joint stirrups was included. The correct interpretation of the code implied the use of joint stirrups, as reflected in best practice manuals in Italy (e.g. Santarella 1977). For such reason, many joint layouts were possible in this period, including configurations similar to the pre-1970 period or (very rarely) better configurations involving stirrups.

49 It is worth mentioning that two more-advanced documents were introduced in this period, respectively the 1996 Structural Code (Consiglio dei Ministri 1996), including its implementation guidelines (Consiglio dei Ministri 1997), and the 2003 
151 Seismic Design Guidelines (Consiglio dei Ministri 2003). In the first document, limit state design was introduced but it was

152 left as an optional alternative to allowable stresses. As a result, the vast majority of practitioners adopted the allowable stresses 153 approach (Manfredi et al. 2011). The 2003 document suggested, rather than enforcing, seismic provisions. Specific minimum requirements for joint stirrups were instead included after 1996.

155 A mapping with international standards is arguably not possible for the class 4 case studies. For example, in the early 1970 s, 156 a clear shift between allowable stress and ULS design is seen in both New Zealand and USA, together with the implementation of capacity design and some level of seismic detailing of the members. In contrast, this shift is not very clear in Italy: for example, ULS design effectively became mandatory only after 2008.

159 Class 5 refers to post-2008 buildings and it is intended as a control group. The longitudinal reinforcement ratio of the columns

160 ranges between $1.57 \%$ and $2.79 \%(1.22 \%-1.67 \%$ for the transverse one), while their axial load ratio is in the range $2 \%-14 \%$.

161 The longitudinal reinforcement ratio of the beams is approximately equal to $1.35 \%$ (the transverse one is approximately equal to $0.58 \%$ ). Buildings in this class are designed based on the 2008 structural code (Consiglio dei Ministri 2008). A displacementbased design approach is used considering seismic loads consistent with the spectral shape prescribed by the same code (peak therefore enforcing a global plastic mechanism. It is worth mentioning that the minimum code requirements for the detailing of the members is expected to cause a level of overdesign (e.g. Ricci et al. 2018).

The different design methods resulted in the reinforcement patterns shown in Table 2 and Figure 1c. In particular, the first four classes have the same configuration of beam and column cross sections (as shown in Figure 1b), including the longitudinal reinforcement pattern. As shown in Table 2, the transverse reinforcement of the 1976-2007 beams and columns is higher. A greater beam reinforcement is provided for post- 2008 frames, and the central beams have the same cross-section of the external ones. To comply with capacity design rules, a greater reinforcement is also assigned to columns. Differently than for the first four classes, columns are not tapered at (the fourth storey) for the six-storeys post-2008 frames. Mapping this class to the up- 
175 both in terms of global strength/ductility and expected plastic mechanism.

176 Table 2. Reinforcement patterns for beams and columns (end cross-sections only).

\begin{tabular}{llll}
\hline Detail & Member & Longitudinal reinforcement & Transverse reinforcement \\
\hline \multirow{2}{*}{ Pre 1976 } & Columns & \multirow{2}{*}{ As per Figure 1c } & $1 \phi 8 @ 200 \mathrm{~mm}$ \\
& Beams & & $1 \phi 8 @ 200 \mathrm{~mm}$ \\
\multirow{2}{*}{$1976-2007$} & Columns & As per Figure 1c & $1 \phi 8 @ 150 \mathrm{~mm}$ \\
& Beams & $1 \phi 8 @ 150 \mathrm{~mm}$ \\
\multirow{2}{*}{ Post 2008 } & Columns & $10 \phi 18$ & $1 \phi 12 @ 100 \mathrm{~mm}$ \\
& Beams & $4 \phi 18+4 \phi 18$ & $1 \phi 8 @ 100 \mathrm{~mm}$ \\
\hline
\end{tabular}

\section{2.2. Selected variables: structural details and material properties}

178 Figure 2 shows the structural details in the exterior joint panels of each class. Such details strongly affect the strut-and-tie

179 mechanism that transfers shear in joint panels (Priestley 1997). After the first concrete diagonal cracking in joints, this shear-

180 transferring mechanism activates, and it involves a diagonal concrete strut and joint shear reinforcement ties. However, if little

181 or no shear reinforcement is present, the strength of the mechanism is entirely based on the concrete strut. For exterior joints,

182 the equilibrium of the concrete strut is provided by the bond stress on the reinforcement bars coming from the beams. Apart

183 from the presence of joint stirrups, the anchorage solution for the longitudinal beam reinforcement is a fundamental aspect

184 controlling the joint shear-carrying capacity, Interior joint panels are less reliant on the structural details and have a higher

185 strength, since the confinement of the left and right beams allows the concrete strut to be balanced.

186 No stirrups are provided for the joints of the first four classes, reflecting the design practise of those periods (e.g. Manfredi et

187 al. 2011). The three most common anchorage solutions for the beam longitudinal bars are the hook, a bent-out and a bent-in

188 configuration, respectively considered for class 1, 2 and 3-4. As reported in Pampanin et al. 2003, the solution leading to the

189 lowest strength is the hook, followed by the bent-out and bent-in configurations, which provide better mechanisms to

190 equilibrate the concrete strut. For class 5, joint panels are assumed to be capacity-protected by a sufficient amount of joint

191 stirrups, whose number is not explicitly calculated and it is shown in Figure 2 only for indicative purposes. The most

192 appropriate parameter for quantifying joint shear strength is the principal stress - typically tensile for exterior, compressive for

193 interior joints - since this can consider the level of axial load. This is typically expressed in the form $k \sqrt{f_{c}}$, where $k$ is the joint 

deformation of the panel. The New Zealand guidelines for seismic assessment (New Zealand Society for Earthquake Engineering (NZSEE) 2017) provide values for both strength and deformation capacity of the joint panels (Figure $4 \mathrm{~b}$ below). formula.

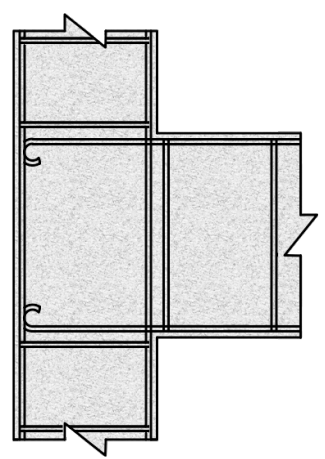

Pre 1976, hook

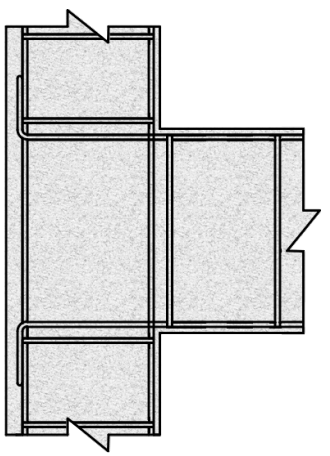

Pre 1976, bent-out

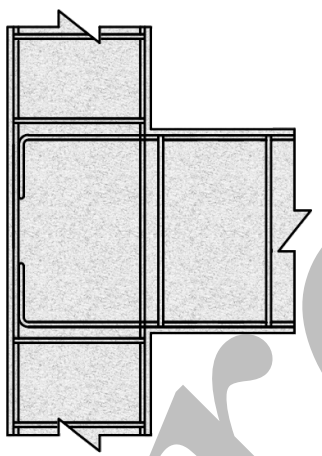

Pre 1976, bent-in

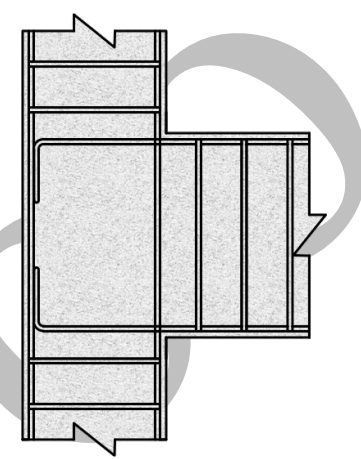

1976-2007

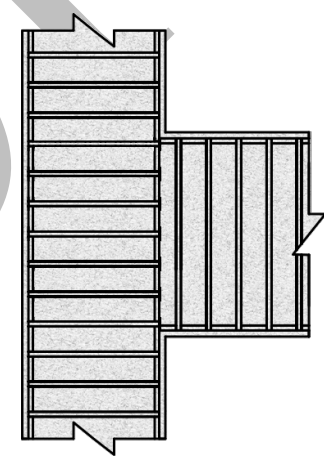

Post 2008

200 Figure 2. Structural details in exterior joint panels. The layout of both splices and anchorage is only indicative.

The material-related random variables selected for this study are the concrete cylindrical compressive strength $\left(f_{c}\right)$ and the steel yield stress $\left(f_{y}\right)$. These are the two properties typically considered in any in-situ test campaign for RC structures. Both variables are described with a normal distribution (Figure 3). Literature studies (e.g. Verderame et al. 2001, Cristofaro et al. 2014, Galasso et al. 2014) show that this is a reasonable approximation for the above variables. Reference concrete and steel material categories are first selected to represent the typical choices according to the Italian material classification of each considered time period. Therefore, statistical analysis on laboratory tests are adopted to characterise the mean and standard deviation $(\sigma)$ of the distributions ( 
Table 3) or, similarly, the coefficient of variation $(\mathrm{CoV})$, i.e., the ratio of the standard deviation on the mean of each parameter.

210 Specifically, concrete properties for the first three classes (Pre 1976) are defined according to Verderame et al. 2001, which 211 includes in-situ tests for real Italian RC buildings constructed up to the 1960s. Results in Cristofaro et al. 2014 are instead 212 adopted for the concrete in the fourth class (1976-2007), which relate to tests conducted in the 1980s. The characterisation of 213 the steel yield stress for the same classes is based on the results by Verderame et al. 2011, which provide means and standard 214 deviations disaggregated for each decade. For class five (Post 2008) mean values equal to 38MPa e 490MPa are respectively 215 selected for concrete strength and steel yield stress. Those represent the mean value of the materials "C $30 / 37$ " and "B450C", 216 respectively. The considered values of $f_{c}$ and $f_{y}$ are sampled according to a nine-factorial DoE (Figure 3) considering equally217 spaced points in the range $[-2 \sigma ;+2 \sigma]$. The minimum considered values of $f_{c}$ are respectively equal to 8.4MPa, 12.1MPa and 218 28.3MPa for classes $1-3,4$ and 5 (269.2MPa, 323.1MPa and 441.4MPa for $f_{y}$ ). This leads to 81 frame samples for each class 219 and geometry (810 case studies in total). This is preferred to a plain Monte Carlo approach since it requires a significantly

220 lower number of samples. It is worth mentioning that no correlation is assumed between $f_{c}$ and $f_{y}$. Moreover, the simulated

221 values of $f_{c}$ and $f_{y}$ are assigned to all the RC members in the frame.
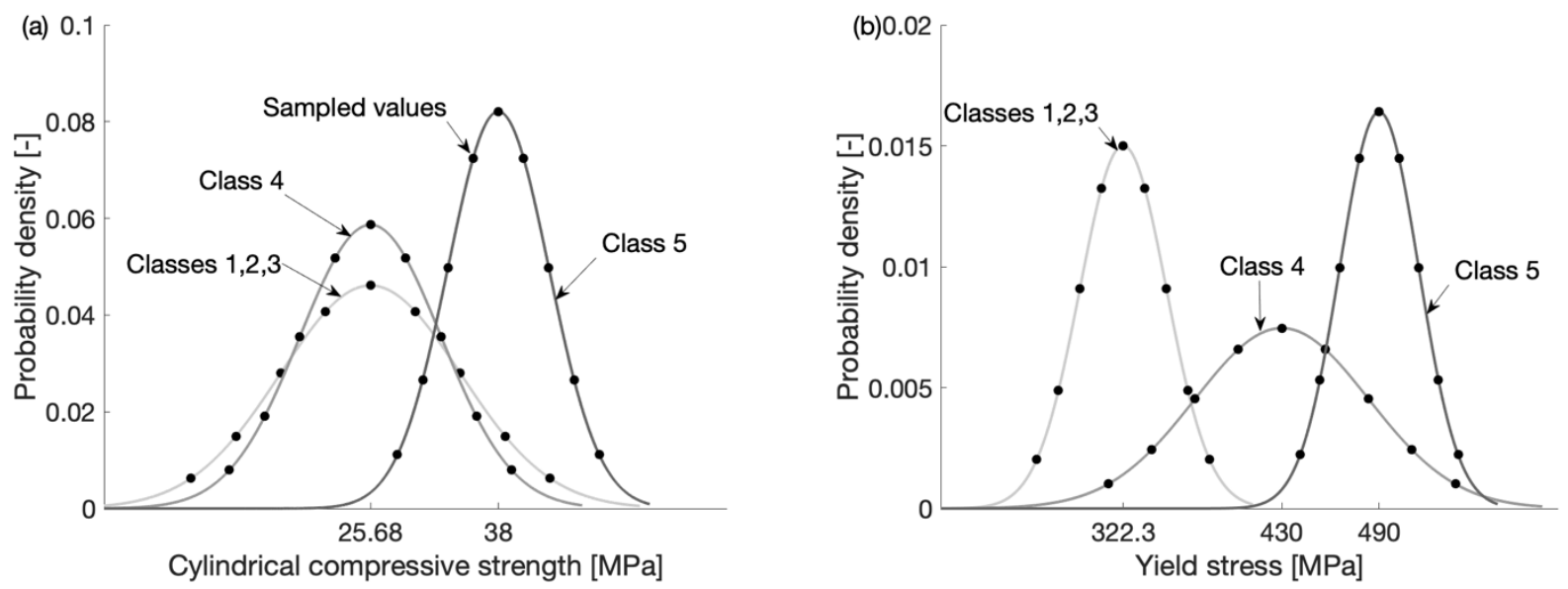

223 Figure 3. Probabilistic distributions for the material properties. a) Concrete cylindrical compressive strength, b) steel yield stress. 


\begin{tabular}{lll}
\hline Detail & Concrete & Steel \\
\hline & & \\
Pre 1976, hook; & "Normale" & "Aq. 42" \\
Pre 1976, bent-out; & $\mathrm{f}_{\mathrm{cm}}=25.7 \mathrm{MPa}$ & $\mathrm{f}_{\mathrm{ym}}=322.3 \mathrm{MPa}$ \\
Pre 1976, bent-in & $\mathrm{CoV}=33.7 \%$ & $\mathrm{CoV}=8.2 \%$ \\
& & \\
& & \\
& "Rck 300" & "Fe B 32k" \\
& $\mathrm{f}_{\mathrm{cm}}=25.7 \mathrm{MPa}$ & $\mathrm{f}_{\mathrm{ym}}=430.0 \mathrm{MPa}$ \\
& $\mathrm{CoV}=26.5 \%$ & $\mathrm{CoV}=12.4 \%$ \\
& & \\
& "C 30/37" & "B $450 \mathrm{C} "$ \\
& $\mathrm{f}_{\mathrm{cm}}=38.0 \mathrm{MPa}$ & $\mathrm{f}_{\mathrm{ym}}=490.0 \mathrm{MPa}$ \\
Post 2008 & $\mathrm{CoV}=12.8 \%$ & $\mathrm{CoV}=5.0 \%$ \\
\hline
\end{tabular}

$\mathrm{f}_{\mathrm{cm}}$ average concrete compressive strength (cylindrical)

Sampling values of $f_{c}$ and $f_{y}$ has a direct effect in the characterisation of the RC beams, columns and joint panels; in particular:

- The flexural capacity of beams and columns is characterised through a moment-curvature analysis (including gravity axial load). The model by Mander et al. 1988 is used for concrete, including the calculation of its ultimate strain (accounting for confinement). King et al. (1986) is used for steel. It is worth mentioning that concrete modulus of elasticity is calculated based on $f_{c}$, and this is done also for the tensile $\left(\varepsilon_{c t}\right)$ and ultimate $\left(\varepsilon_{c u}\right)$ concrete strain;

- Plastic hinge length is calculated according to Priestley and Park (1987), which depends on $f_{y}$;

- Bar buckling is calculated according to the deformation-based model by Berry and Eberhard (2005), which depends on both $f_{c}$ and $f_{y}$;

- The shear capacity of beams and columns is calculated according to Kowalsky and Priestley (2000), which depends on both $f_{c}$ and $f_{y}$. This force-controlled check is based on the intersection (if any) of the force-displacement curve of the member (flexure) with the deformation-dependent shear strength;

- Using the Mohr's circle approach, the joint shear stress capacity is calculated such that its principal/compressive stress capacity is achieved (proportional to $\sqrt{f_{c}}$ ). 
As an example, Figure 4a shows the effect of the 81 material samples on the flexural capacity of an exterior base column in the three-storey frame of the Pre 1976 class. This is compared with the effect of structural details on the capacity of exterior joint panels (Figure 4b).
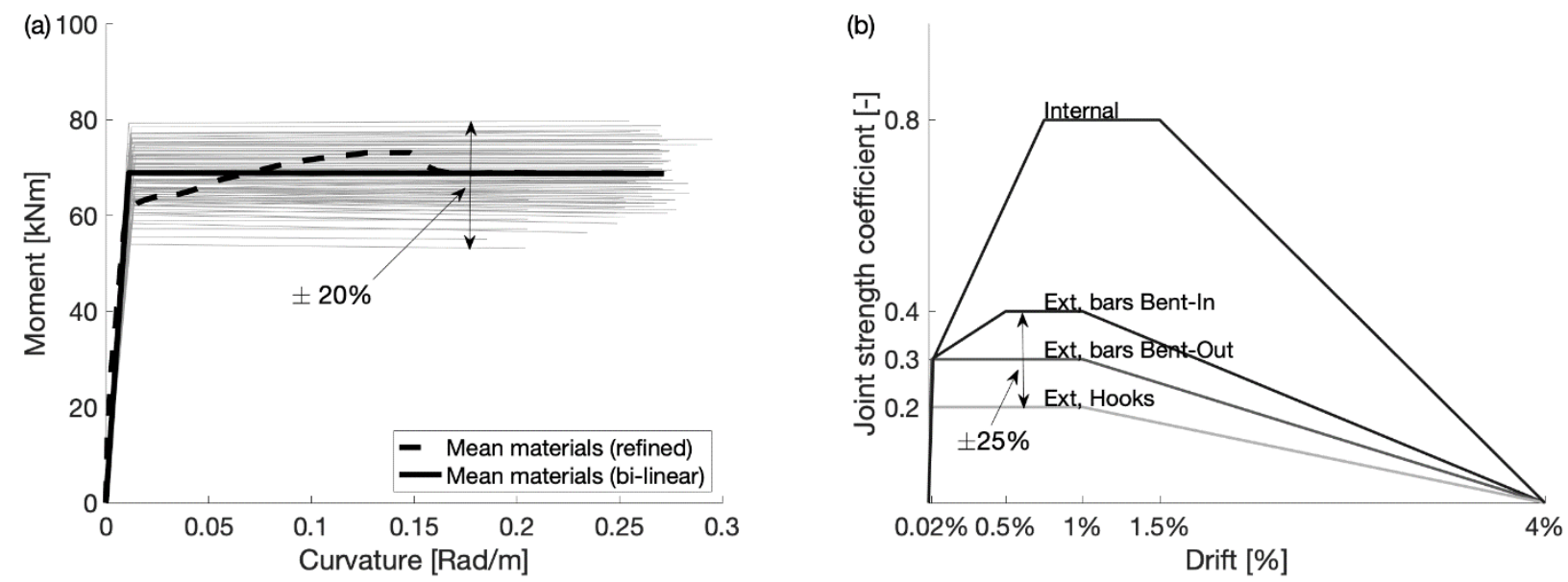

Figure 4. a) Effect of material strength on base external column capacity (three-storey frame, detail 3), b) effect of structural details on capacity of joint panels.

\section{2.3. Performed analytical calculations and numerical analyses}

248 Each of the 810 sampled frames is analysed by means of SLaMA and a numerical pushover. The ten structural models 249 characterised by the mean values of the material properties are also analysed with NLTHA for validation purposes. SLaMA 250 (New Zealand Society for Earthquake Engineering (NZSEE) 2017; Gentile et al. 2019a, b, c, d) gives the estimation of both 251 the plastic mechanism and the capacity curve (i.e. a force-displacement curve) of RC frame, wall and dual-system buildings 252 by using a "by-hand" procedure (i.e. using an electronic spreadsheet). This method is based on the calculation of the hierarchy 253 of strength at sub-system level (beam-column joint sub-assemblies for frame structures) and the adoption of equilibrium and 254 compatibility principles to "assemble" the local results to obtain the global capacity curve. SLaMA is adopted to identify 255 potential structural weaknesses in the lateral resisting mechanism and to test the reliability of numerical computer models in 256 capturing the behaviour of the case study frames. Beams, columns and joint capacities are characterised as described above, 257 considering that the weakest link will govern the overall behaviour. 
Refined numerical pushover analyses are carried out with the finite element modelling software Ruaumoko2D (Carr 2016), to

259 have a second level of refinement in the analyses. The modelling strategy (Figure 5) is based on a lumped plasticity approach 260 which was validated on experimental results (Magenes and Pampanin 2004). RC members are characterised as described 261 above, including a linear strength degradation such that the moment capacity is zero when the drift is equal to twice the near262 collapse one. In particular, joint panels are modelled with non-linear springs connecting adjacent beams and columns. The 263 behaviour of the springs is represented by equivalent column moment vs drift curves (NZSEE 2017), defined consistently with 264 Figure 4b. P-Delta effects are considered in the model, although they are not deemed to be substantial for three- and six-storey 265 frames (as demonstrated by Gentile et al. 2019a). Floor diaphragms are modelled as rigid in their plane, and fully fixed 266 boundary conditions are considered at the base. A linear force profile is adopted.

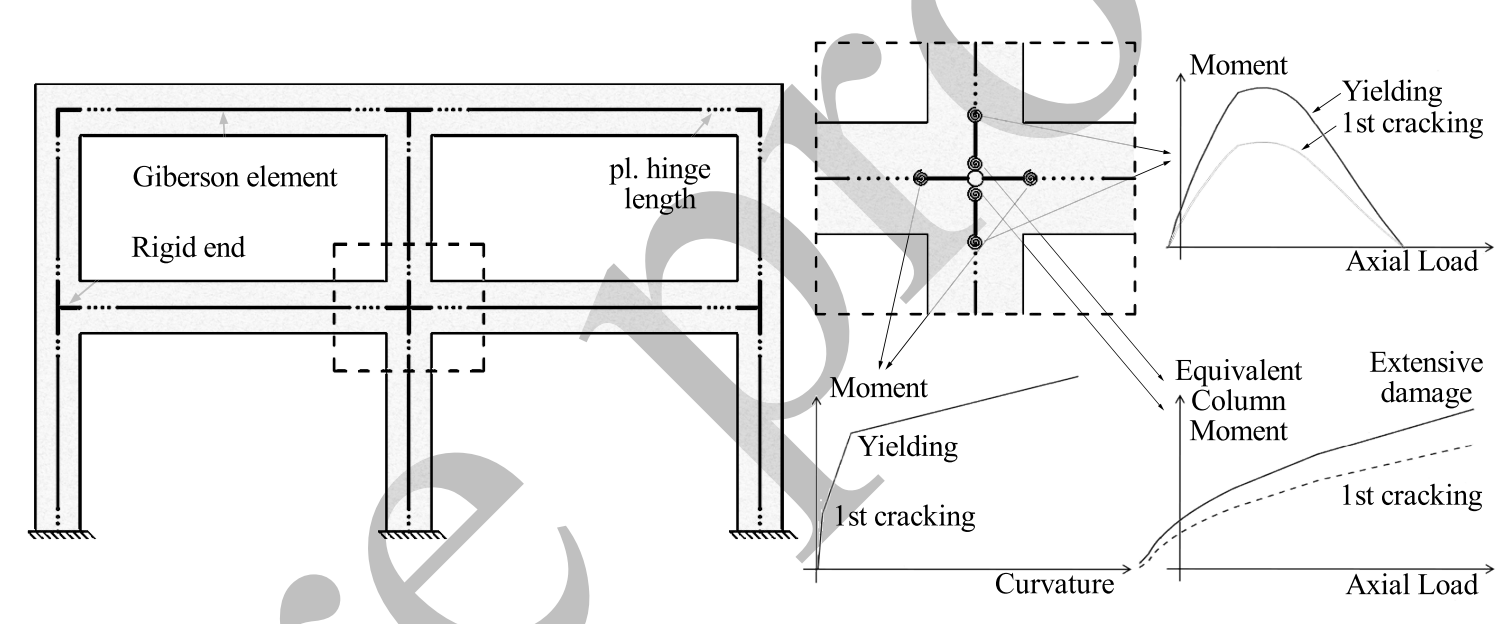

268 Figure 5 Numerical modelling strategy (Gentile et al. 2019a).

269 Considering the 240 ground-motion records described above, the CSM (Freeman 2004) is performed to calculate the response 270 of each structure (i.e., the performance point), both using the SLaMA- and the pushover-based capacity curves. The CSM is 271 carried out using the effective height, effective mass and equivalent viscous damping formulations provided by Priestley et al. 272 2007. No bi-linearisation of the capacity curve is considered. The maximum inter-storey drift is the chosen engineering demand 273 parameter (EDP), and it is calculated adopting the displacement shapes used in Gentile et al. 2019a. Six ground-motion sets 274 are defined (see Section 2.4), consistent with the seismic hazard at a target site for a given mean return period, and scaled at 
the same value of the spectral acceleration at the fundamental period (intensity measure, IM). In this way, the application of the CSM is consistent to the multiple stripe analysis procedure (MSA, Jalayer and Cornell 2009).

277 Refined seismic estimates of the EDP values, for the ten case studies with mean values for the materials, are derived with 278 NLTHA using the same ground-motion record sets. The above-mentioned numerical models are used herein, using the revised 279 Takeda hysteretic model (Saiidi and Sozen 1979) for beams and columns, with the columns having a thinner loop. The 280 hysteretic behaviour of the beam-column joints is modelled using the Modified Sina model (Saiidi and Sozen 1979), which is 281 able to capture their pinching behaviour.

282 Four lognormal fragility curves are fitted to each of the available ensembles of IM vs EDP pairs, one for each considered DS.

283 Details on the definition of the DSs, including the related drift thresholds, are discussed below. As proposed by Baker (2015),

284 the fitting is performed with the maximum-likelihood estimation approach, and considering a binomial link function.

\section{2.4. Ground-motion record sets}

286 The case-study site for this study represents a high-seismicity area in Italy (Cosenza) characterized by soil type B according 287 to Eurocode 8. The reference seismic hazard for the site is calculated according to the European seismic hazard model 288 (ESHM13) presented in Giardini et al. 2014, including the definition of uniform hazard spectra (UHSs) for six exceeding 289 probabilities $(50 \%, 39 \% 10 \%, 5 \%, 2 \%$ and $1 \%)$ in 50 years (or equivalently, for six mean return periods equal to $72,102,475$, 290975,2475 , and 4975 years). Using the UHS as a target spectrum for the record selection may produce conservative estimates

291 of the median limit-state accelerations (e.g. Baker and Cornell 2006). More advanced record selection procedures might be used to improve this aspect, such as the conditional spectrum (Lin et al. 2013) or the generalised conditioned intensity measure 293 (GCIM; Bradley 2010) approaches, as discussed for example in Tarbali et al. (2019). However, the approach used here is

294 deemed acceptable for the aims of this study, since only the relative quantification of the different epistemic-uncertainty effects 295 is investigated. Moreover, the considered record-selection procedure is consistent with the current state of practice in real 296 record selection for several seismic analysis applications (e.g. Iervolino et al. 2010). 
297 Specifically, for each target mean return period of the seismic action, the record selection process is performed through three 298 steps. First, hundreds of candidate ground motions are selected based on the hazard disaggregation in terms of the considered

299 IMs, considering the target hazard in Cosenza and the next generation attenuation relationships for western US (NGAWest2) 300 database (Ancheta et al. 2014). For this selection, the considered shear wave velocity in the first $30 \mathrm{~m}$ of soil for each ground

301 motion is approximately equal to $400 \mathrm{~m} / \mathrm{s}$. The candidate records are therefore linearly scaled to match the spectral acceleration 302 at the building first mode vibration period, $S_{a}\left(T_{1}\right)$, of the above-mentioned target UHS. The considered maximum scale factor 303 is equal to 5. Finally, the misfit of the scaled individual spectra, with respect to the UHS, is calculated according to Eq. (1), 304 and the 40 ground motions with the lowest misfit are selected. In such equation, $T_{i}$ is the $i^{\text {th }}$ period within the range [0.2T $\left.3052 T_{1}\right] . T_{i}$ are equally-spaced with a step of $0.1 \mathrm{~s}$.

$$
\text { misfit }_{j}=\sqrt{\sum_{i} \log \left(\frac{S_{a}^{j}\left(T_{i}\right)}{S_{a}^{\text {target }}\left(T_{i}\right)}\right)^{2}}
$$

306 Figure 6 shows the first mode periods of the sampled frames, also indicating that the median values for the three- and sixstorey frames are equal to $0.5 \mathrm{~s}$ and $0.78 \mathrm{~s}$, respectively. Considering the spectral acceleration $S_{a}(0.5 s)$ and $S_{a}(0.78 s)$ as the selected IM, two different ground-motion sets (Figure 7) are selected, and respectively used for the three- and six-storey frames.

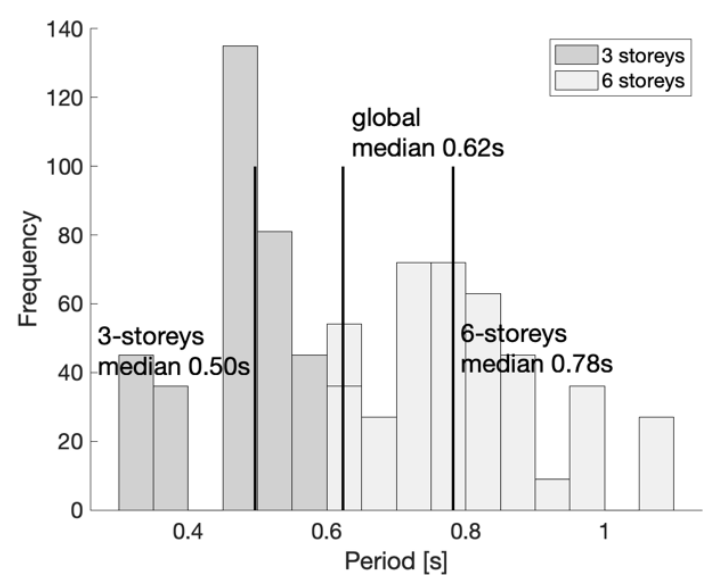

310 Figure 6. Fundamental period of the case study buildings, including variations of materials and structural details. 
312 The fragility curves derived for each sampled frame are used for the relative quantification of the effects due to material

313 uncertainties and structural details in the joint panels. For each building class and building height, a fragility curve that embeds

314 all the materials-related samples is calculated, considering both the record-to-record variability and the material epistemic

315 uncertainties together $(\mathrm{R} 2 \mathrm{Rm})$. This is essentially the expected value of the seismic fragility (for the $\mathrm{k}^{\text {th }} \mathrm{DS}$ ) and it is calculated

316 by means of the total probability theorem. In particular, the resulting fragility curve is a weighted summation of the individual

317 fragility ones for each sample of $f_{c}$ and $f_{y}$, weighted by their probabilities of occurrence. Accepting a small error, the resulting 318 cumulative distribution function (CDF) - i.e., the fragility - is represented here as a lognormal CDF. The logarithmic dispersion $319 \beta_{R 2 R m}$ of the obtained CDF is used as a proxy for the epistemic uncertainty effect related to the materials.
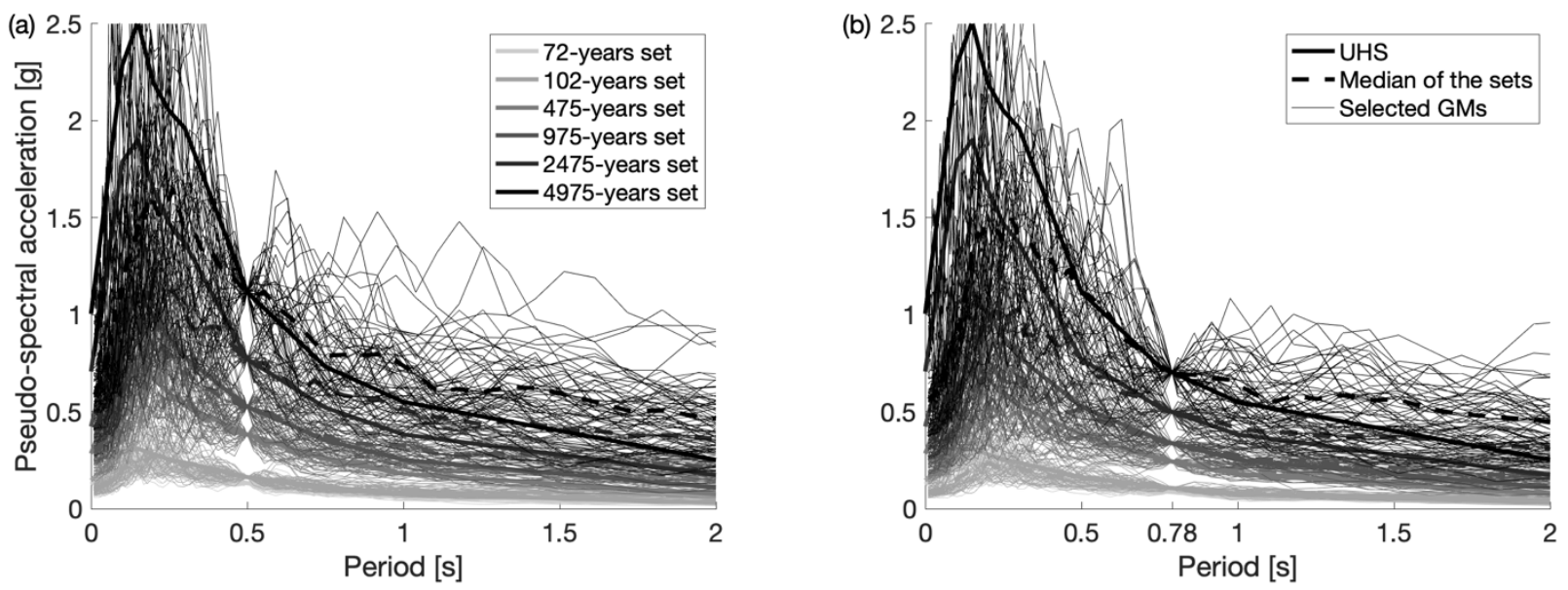

321 Figure 7. Selected ground motions for a) three-storey buildings, b) six-storey buildings.

322 A similar approach is adopted for structural details. For a given building height, a fragility curve that embeds the R2R and the

323 detail-related variations (R2Rd) is derived. The logarithmic dispersion $\beta_{R 2 R d}$ of such CDF is used as a proxy for the sensitivity

324 of the seismic fragility to the structural details. In this case, the total probability theorem is applied to the fragility curves of

325 the first four classes, considering mean material values $\left(f_{c m}, f_{y m}\right)$ and the probability $p\left(\right.$ class $\left._{i}\right)$ of observing the $\mathrm{i}^{\text {th }}$ class. Three considerations are necessary herein: 1) as mentioned in Section 2.1, it is likely that a building constructed in the period 1976- 
327

1996 has joint details similar to the pre 1976 period. This justifies considering classes 1 to 4 in the R2Rd calculation (as opposed to classes 1 to 3); 2) class 5 (modern buildings) is not considered since it is highly unlikely that an existing RC frame would have such modern structural details; 3) to reflect the lack of accurate statistics related to joint details in existing structures, a uniform distribution for the joint details is adopted.

\section{RESULTS AND DISCUSSION}

\subsection{Results of the non-linear static analyses}

The results of both the numerical pushover analysis and the SLaMA approach are first summarised in Figure 8, considering the case studies with the mean values of the material properties. Those are represented in terms of roof drift versus base shear $\left(V_{B}\right)$ normalised by the total building weight, $W$ (i.e. the base shear coefficient is used). Results for the entire dataset are shown in Figure 9, including the typical plastic mechanisms for each class, calculated at the onset of DS3. It is worth mentioning that the curves are truncated at DS3 for readability. Figure 8 shows that the base shear capacity of the sampled buildings is fairly similar for the first three classes; it slightly increases for class four while being considerably higher for modern buildings (class five). A similar pattern is shown for the displacement capacity, although the increase from the first to the third class is considerably higher, due to the different details in the joint panels.
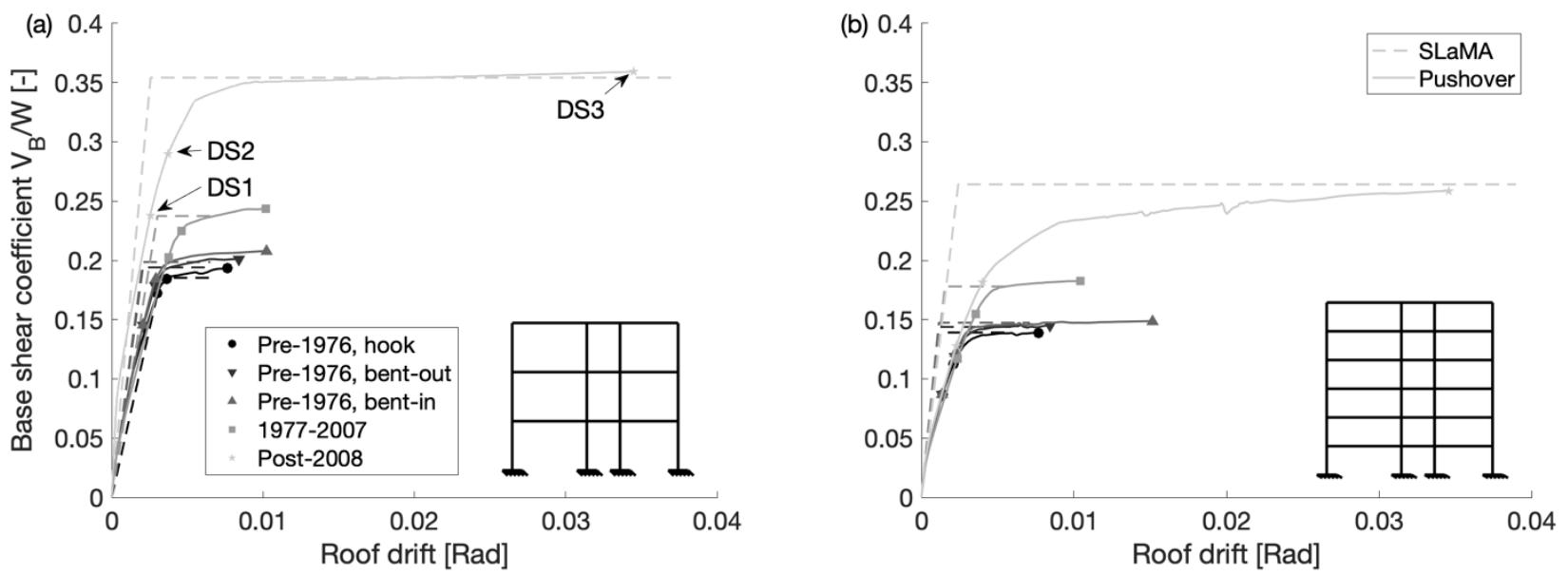
343 Such figure also allows to discuss the DS thresholds adopted for the fragility analysis, which are detailed in Table 4. In 344 particular, each DS is located on the pushover curve, and the corresponding maximum inter-storey drift is retrieved from the 345 numerical analysis results. The thresholds are defined for each sampled frame, and within one class and height level the median 346 values are used (rounded to the nearest 0.05 ). Since this paper focuses on relative results only, no variability of the DS 347 thresholds is herein considered.

348 Four DSs are considered for this study. DS1 corresponds the first cracking of the first member in the frame. Negligible 349 variations are observed for the DS1 limit, which is therefore constant for all the classes. DS2 corresponds to the yielding of 350 the first member (highlighted with a blue circle in Figure 9). For class 1, both columns and joint panels contribute to the 351 deformability of the frame, and therefore the DS2 threshold for class 1 is higher than for classes 2 and 3, for which mainly 352 joints are contributing. The DS2 threshold for class 4 is the same as classes 2 and 3, since columns are equipped with higher 353 reinforcement (especially the transverse one) and joints mainly contribute to the deformability of the frame. The DS2 threshold 354 for class 5 is slightly higher, since buildings of this class are comparatively stiffer and stronger than the other classes. The DS3 355 drift is related to the life-safety performance (ULS). This refers to the first member in the frame that reaches its life-safety 356 deformation (highlighted with a red circle in Figure 9). The first three classes are governed by the joint panels, which have 357 increasing efficiency in the details. The DS3 threshold for class 4 is also governed by the joint panels, given the stronger 358 columns. However, a higher DS3 drift is selected for class 4 structures since they allow for a better redistribution of the internal 359 actions before the first joint panel reaches DS3. Finally, the DS3 drift threshold for class 5 is higher since this is governed by 360 the ultimate strain in the first beam. DS4 is related to the near collapse condition. Complying to the suggestions in Eurocode 3618 , this is set equal to four thirds of the DS3 threshold. The drift thresholds for the six-storey frames are comparatively smaller 362 than the three-storey ones, given their increased height and the larger non-linearity in their displacement shape. 


\begin{tabular}{llllll}
\hline \multirow{2}{*}{ Storeys } & Detail & DS1 & DS2 & DS3 & DS4 \\
\hline 3 & 1 & 0.20 & 0.55 & 1.00 & 1.30 \\
& 2 & 0.20 & 0.45 & 1.15 & 1.55 \\
& 3 & 0.20 & 0.45 & 1.60 & 2.15 \\
& 4 & 0.20 & 0.45 & 1.90 & 2.55 \\
6 & 5 & 0.20 & 0.60 & 4.50 & 6.00 \\
6 & 1 & 0.15 & 0.30 & 0.60 & 0.80 \\
& 2 & 0.15 & 0.25 & 0.80 & 1.05 \\
& 3 & 0.15 & 0.25 & 1.00 & 1.35 \\
& 4 & 0.15 & 0.25 & 1.50 & 2.00 \\
& 5 & 0.15 & 0.35 & 4.20 & 5.60 \\
\hline
\end{tabular}

365 The typical DS3 plastic mechanisms of each class and height level are shown in Figure 9. The first three classes show a Mixed-

366 Sway mechanism, in which a combination of beam, column and/or joint failures are triggered. Such mechanisms are

367 particularly "insensitive" to the samples for the material properties, and the member that causes DS3 is typically a joint panel.

368 However, for the six-storey, class 3 frames with higher $f_{c}$ and $f_{y}$ values, joint failure is prevented, the mechanism changes and

369 DS3 is caused by a column. This increases the variability in the pushover curves, which is considerably lower for the other

370 classes. For class 4, such Mixed-Sway mechanism is even more evident, since the higher reinforcement in columns prevents

371 their flexural failure. Such increased reinforcement leads to a higher sensitivity of the pushover curves to the samples of $f_{y}$.

372 The typical plastic mechanism for class 5 is a Beam-Sway, in which all the beams are forming plastic hinges, together with

373 the base of the columns. Such mechanism is insensitive to the samples of $f_{c}$ and $f_{y}$, and this is also reflected on the pushover

374 curves.

375 As shown by Gentile et al. 2019a, the SLaMA-based curves generally match the pushover ones in the non-linear branch, but

376 show a considerably-higher discrepancy around the global yielding (due to the assumed bi-linearisation in SLaMA). Such

377 discrepancy is also reflected in the estimation of the initial stiffness of the curve, which is typically over-estimated in SLaMA.

378 The above-mentioned discrepancies are more evident for the six-storey frames (given the higher number of members) and for

379 class 5 frames (given the higher strength). 
381 A validation of the fragility analysis results based on SLaMA and numerical pushover analyses is presented by means of 382 comparison with the results of time-history analyses. This is done for the sample frames having the mean properties of the 383 materials (ten case studies). As an example, Figure 10 shows the detailed results for the three-storey, class 3 frame. On the 384 other hand, Table 5 shows the relative errors, with respect to time-history analysis, calculated for the median and logarithmic 385 dispersion of the DS3 and DS4 fragilities, both based on pushover and SLaMA.

386 Figure 10a shows the particularly good match between SLaMA and the pushover analysis. The two capacity curves show only 387 minor discrepancies, while differ considerably for very high displacements, since strength degradation is not considered in 388 SLaMA. Moreover, the summary of the hierarchy of strength calculated with SLaMA is consistent with the DS3 plastic 389 mechanism calculated through the pushover analysis. The differences in the two plots are due to the step-by-step distribution 390 of the internal actions, which is not considered in SLaMA. Figure 10b shows the seismic response of the frame to the above-
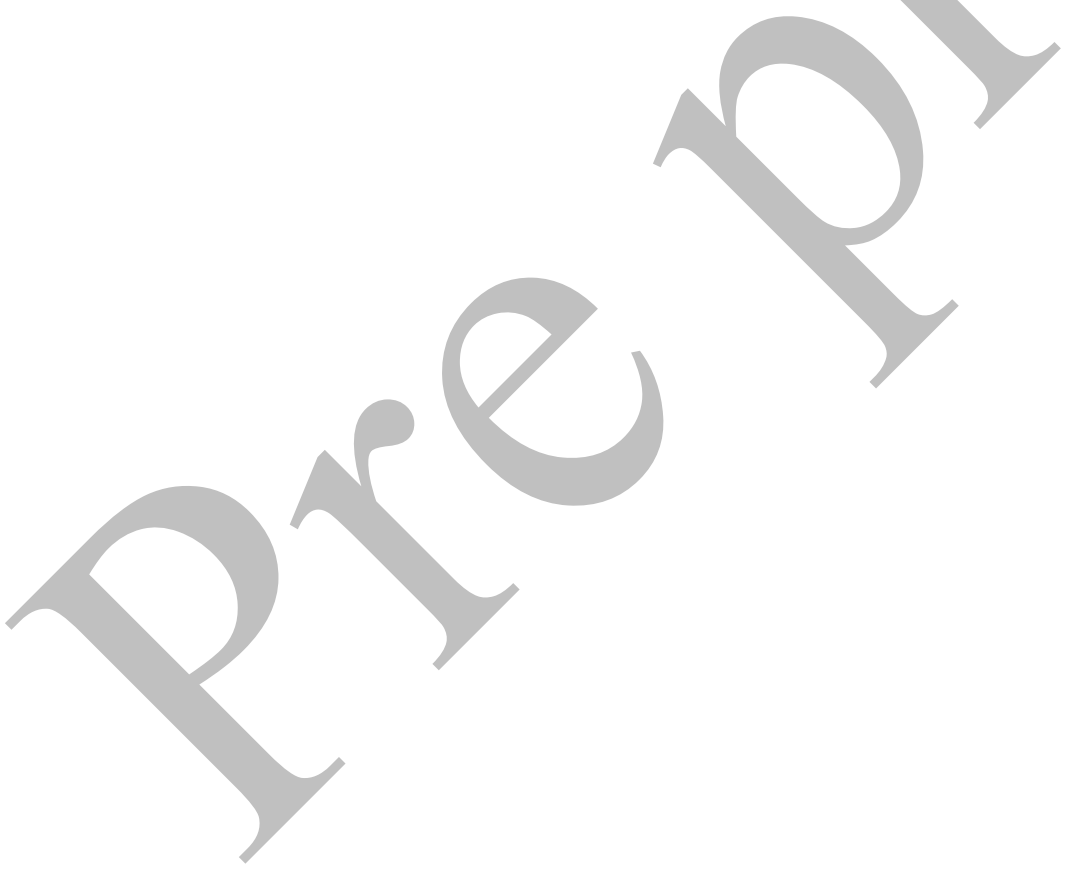

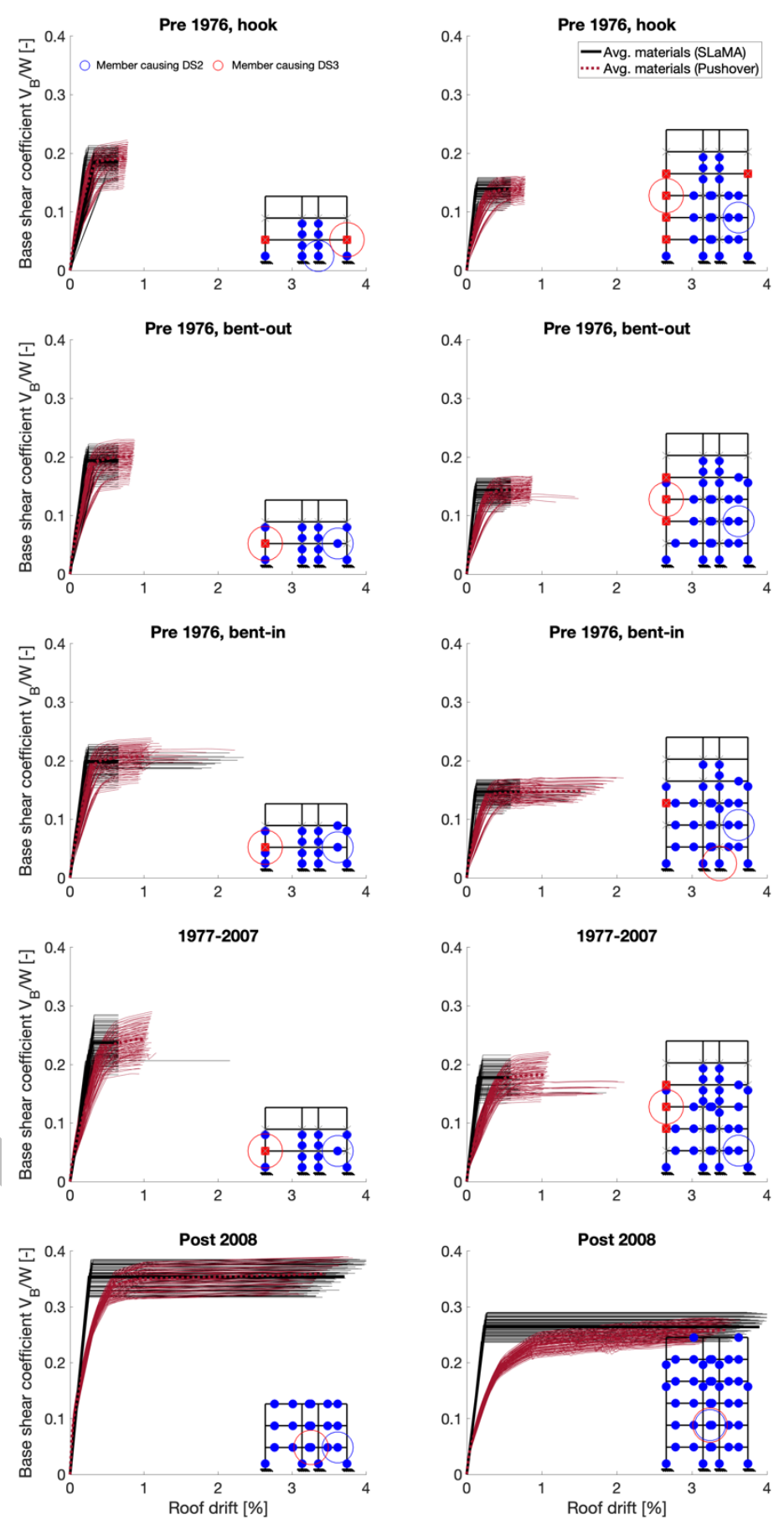

392 Figure 9. Non-linear capacity curves for the entire dataset, including pushover-based plastic mechanism (at the onset of DS3) for 393 average materials. The snapshots plastic mechanisms correspond to the DS3 inter-storey drift levels shown in Table 4. 
mentioned 240 ground-motion records, obtained using the SLaMA- and pushover-based CSM and the full time-history

395 396 especially for DS3 (13.2\% and 10.4\% for pushover and SLaMA).

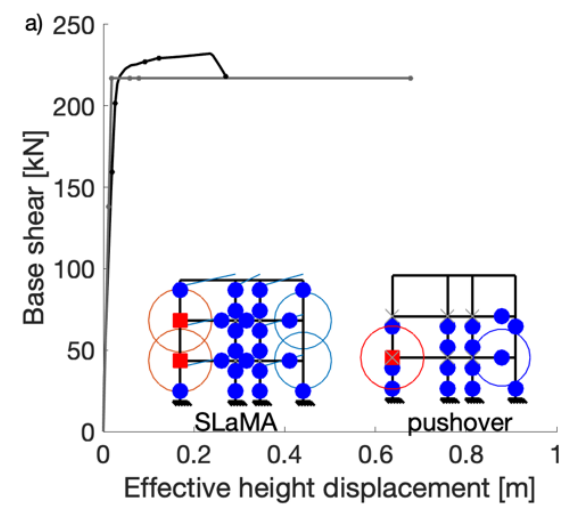

400 curves. higher (maximum 20.1\% and 68.7\%, respectively for pushover and SLaMA).

analyses. A satisfactory match is shown among the three approaches, with higher discrepancies shown for very high values of the IM (due to strength degradation). This result is reflected on the fragility curves in Figure 10c, which are in good agreement for the four considered DSs. The discrepancy with respect to the time-history approach is smaller than $5 \%$ for the pushoverbased median estimates (smaller than $8 \%$ for SLaMA). The error increases for the estimation of the logarithmic dispersion,
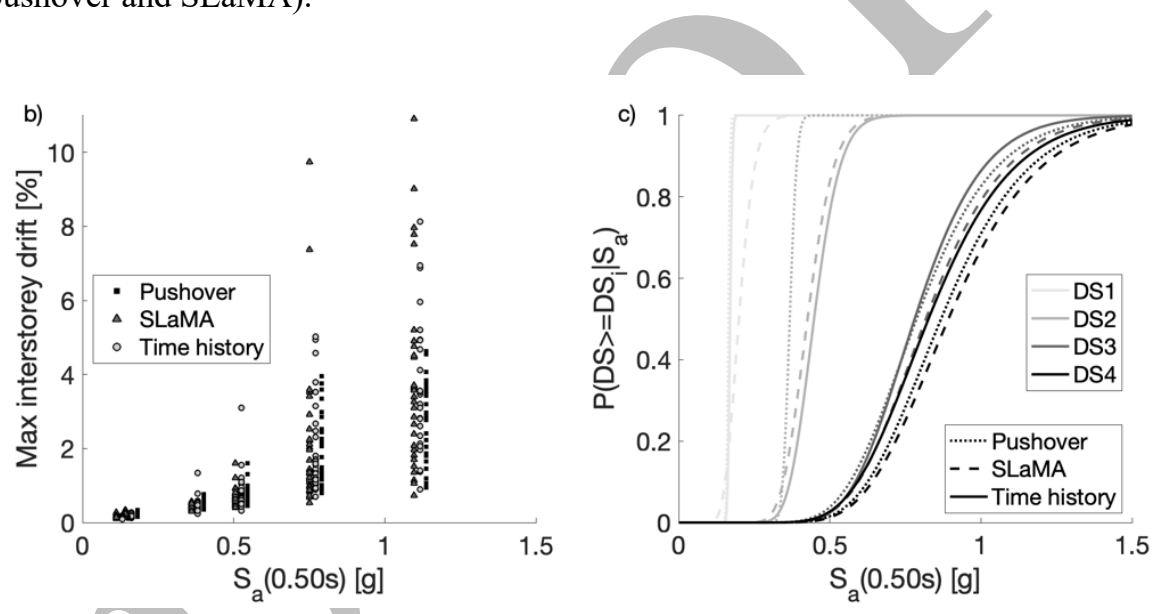

Figure 10. Three-storey, class 3 frame with $f_{y}=322 M P a$ and $f_{c}=26 M P a$. a) non-linear static analyses, b) IM vs EDP stripes, c) fragility

Table 5 shows that the above-mentioned error trends are valid for all the three-storey frames. However, such errors increase in the case of the six-storey frames. This is due to lower accuracy of the CSM for taller frames, for which higher modes are more relevant. For this particular situation, the participating mass of first vibration mode is approximately equal to $90 \%$ and $75 \%$ for the three- and six-storey frames, respectively. Moreover, due to the bi-linear representation of the capacity curve (higher initial stiffness), SLaMA shows a comparatively-higher bias on the seismic response at low levels of the IM. This is mainly affecting the logarithmic dispersion of the fragility curves, for which the error with respect to time-history analyses is

10 Such error trends are not deemed to jeopardise the estimation of the relative effect on seismic fragility of materials and structural details, which is the final goal of this paper. Indeed, the calculations for the R2R+materials fragilities involve frames 
sampled from the same class and height level, for which a similar level of bias is expected. This applies also for the

413 R2R+structural details fragilities, which involve only frames within a given height level. However, to provide the highest level

414 of accuracy (among the adopted approaches), the pushover-based fragilities are used in the next section to quantify the 415 sensitivity.

416 Table 5. Relative errors [\%] of the pushover-based fragilities with respect to time-history analysis (results for SLaMA are 417 shown in brackets).

\begin{tabular}{|c|c|c|c|c|c|c|c|c|c|c|c|c|c|c|}
\hline \multirow{2}{*}{$\begin{array}{l}\text { Storeys } \\
3\end{array}$} & \multirow{2}{*}{$\begin{array}{l}\text { Detail } \\
1\end{array}$} & \multicolumn{4}{|c|}{$\operatorname{Err}\left(\mu_{D S 3}\right)$} & \multicolumn{4}{|c|}{$\operatorname{Err}\left(\mu_{D S 4}\right)$} & \multicolumn{2}{|c|}{$\operatorname{Err}\left(\beta_{D S 3}\right)$} & \multicolumn{3}{|c|}{$\operatorname{Err}\left(\beta_{D S 4}\right)$} \\
\hline & & -12.9 & ( & -9.3 & ) & -6.6 & ( & -4.7 & ) & -18.4 & $(-13.7$ & -21.4 & -15.9 & ) \\
\hline \multirow{9}{*}{6} & 2 & -0.9 & ( & 7.6 & ) & 0.1 & ( & 3.1 & ) & -7.8 & 3.5 & 17.1 & 3.8 & ) \\
\hline & 3 & 0.8 & ( & 4.8 & ) & 5.0 & ( & 8.0 & ) & 13.2 & 10.4 & -1.9 & -0.9 & ) \\
\hline & 4 & -2.5 & ( & 4.1 & ) & -2.7 & ( & -0.4 & ) & -10.0 & -5.8 & -24.0 & -18.0 & ) \\
\hline & 5 & -4.2 & ( & -2.3 & ) & -8.9 & ( & -5.4 & ) & -4.1 & -8.3 & -15.3 & -10.7 & ) \\
\hline & 1 & -14.5 & ( & -17.1 & ) & -24.6 & ( & -24.0 & ) & -1.2 & 41.7 & -2.2 & -66.2 & ) \\
\hline & 2 & -17.4 & ( & 18.0 & ) & -19.7 & ( & -16.8 & ) & -14.2 & -57.7 & -18.1 & -36.5 & ) \\
\hline & 3 & 18.7 & ( & 24.8 & ) & -0.4 & ( & 5.5 & ) & -8.5 & -40.2 & -12.8 & -59.8 & ) \\
\hline & 4 & 1.1 & ( & 3.9 & ) & 1.8 & ( & 2.1 & ) & -4.9 & -39.9 & -8.3 & -38.1 & ) \\
\hline & 5 & 4.6 & ( & 10.0 & ) & 0.7 & ( & 5.0 & & -16.7 & -68.7 & -20.1 & -53.7 & ) \\
\hline
\end{tabular}

418

419

422

\subsection{Sensitivity of the seismic fragility}

To provide a qualitative overview, Figure 11 shows the pushover-based fragility curves for each sampled frame, together with the typical DS3 plastic mechanisms. Solid thick lines show the fragility curves related to the mean values of the material properties (R2R), while dashed lines show the ones including the material-related uncertainty (R2Rm). The DS4 fragilities are not shown to improve the readability of the plots, although their trends are particularly similar to the ones related to DS3.

As expected, the median of the fragility curves increases with the considered class, with class 5 showing significantly higher values. Including the material-related epistemic uncertainty leads to a negligible shift in the in the estimation of the median fragility, consistently with findings in the literature (e.g. Kosič et al. 2012). Within each class and building height, the effect of material variability on the logarithmic dispersion increases with the considered DS (as reported in the literature), although this effect is not particularly large. A comparatively higher effect is seen for the shift in the median fragility due to the structural details. However, such increase is particularly small for DS1 and DS2. This reflects the pushover results and, in turn, the considered drift thresholds for each class (Table 4). Those are particularly similar for DS1 and DS2 (essentially elastic behaviour) while change considerably for DS3 and DS4, where the observed plastic mechanism plays a major role. 

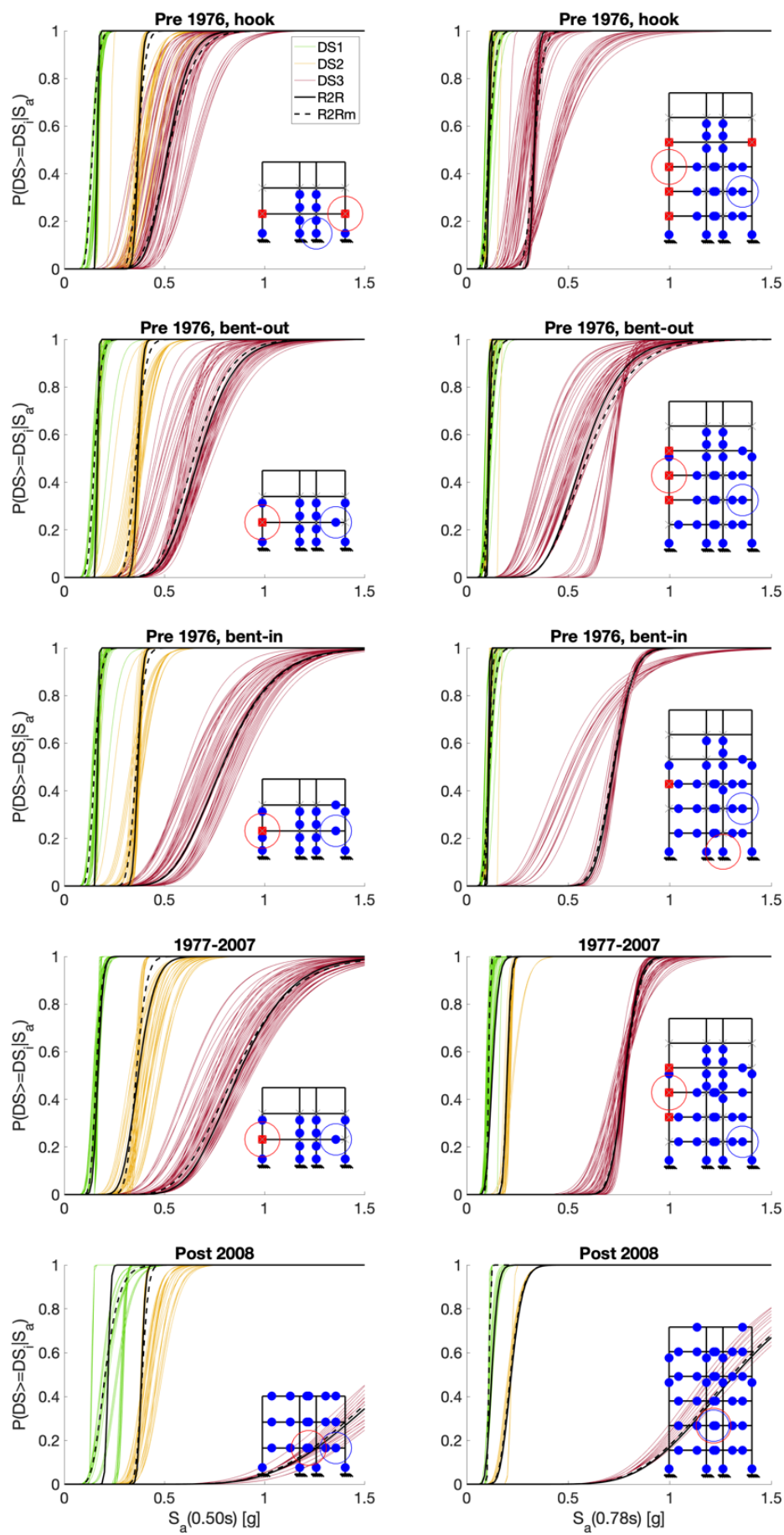

432 Figure 11. Pushover-based fragility curves for the entire dataset (DS1-DS3; DS4 is not shown for readability). 
The relative effect of materials and structural details on seismic fragility is quantitatively assessed in Figure 12, Table 6 and

434 Table 7. To provide a fair comparison, class 5 (related to modern frames) is excluded from such figure/tables. In fact, it is

435 highly unlikely that an existing RC frame would have such modern structural details.

436 Focusing on DS3 (Life Safety), Figure 12 shows the R2R fragility curves in greyscale solid lines and the R2Rm curves in 437 greyscale dashed lines. The fragility curves combining record-to-record variability and structural details effects (R2Rd) are 438 shown in a red dashed line. The increase in logarithmic dispersion due to the materials is maximum equal to 0.03 for the threestorey frames, and 0.06 for the six-storey ones. Contrarily, such increase is respectively equal to 0.14 and 0.38 maximum if the structural details uncertainty is added to the record-to-record one. Similar trends are observed the median fragility: materials cause a maximum shift equal to $0.02 \mathrm{~g}$ (both for three-and six-storey frames), while structural details cause a maximum shift equal to $0.17 \mathrm{~g}$ and $0.34 \mathrm{~g}$, for three- and six-storey cases.
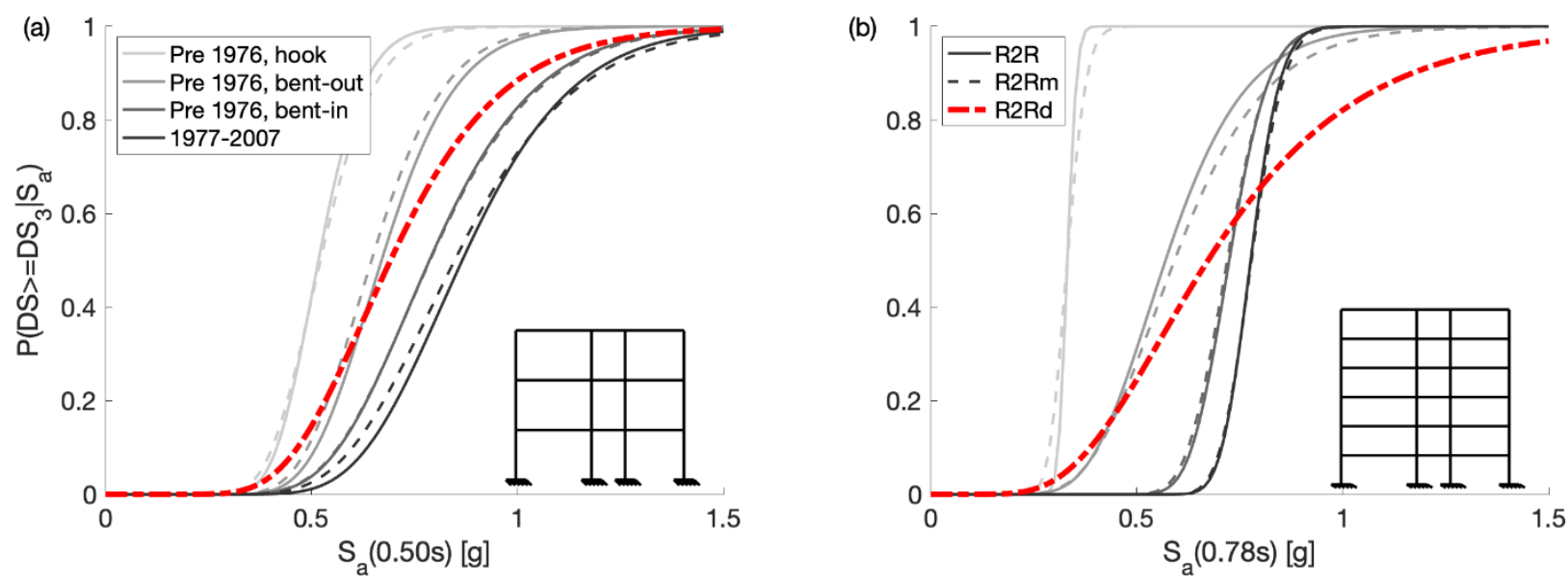

444 Figure 12. DS3 fragility curves (pushover-based). a) three-storey buildings, b) six-storey buildings. "R2R": record-to-record 445 variability; "m": material variability; "d": structural details variability (details 1-4).

446 Structural details have a comparatively higher effect than materials also for DS4 (Near Collapse), as Table 6 and Table 7 show. 447 A different trend is instead observed for DS1 and DS2. Such damage states are respectively governed by the first RC member 448 in the system attaining first cracking and yielding, respectively. Although the concrete tensile (cracking) strain is dependent 449 on concrete strength, the effects of its variation on the member cracking drift are practically negligible. On the other hand, the 
450 yielding of RC members is only dependent on their geometry (Priestley et al. 2007). At global level, the DS2 inter-storey drift

451 threshold can be caused by different RC members (beams, column, joints). For this reason, DS2 is mainly affected by structural

452 details only, although the effect is minimum, and very similar thresholds are required for different frame classes (see Table 4).

453 For these reasons, material-related uncertainty causes a maximum decrease equal to $0.01 \mathrm{~g}$ to the DS1-DS2 median fragility

454 prediction, for all the case studies. The related maximum increase in the DS1-DS2 logarithmic dispersion is equal to 0.06 .

455 Compared to the materials, structural details have a comparable effect on the DS1-DS2 median and a smaller one for the

456 logarithmic dispersion. From a practical point of view, structural details do not increase the DS1-DS2 logarithmic dispersion

457 with respect to the record-to-record case (the increase is smaller than 0.01). This result is in line with the expected behaviour

458 of the sampled frames at DS1-DS2, which is practically independent from the adopted materials and structural details.

459 Table 6. Materials vs structural details: effects on the DS3 pushover-based fragility dispersion.

\begin{tabular}{|c|c|c|c|c|c|c|c|c|c|c|c|c|}
\hline \multirow[b]{2}{*}{ Storeys } & \multirow{2}{*}{ Detail } & \multicolumn{3}{|c|}{ DS1 } & \multicolumn{2}{|r|}{ DS2 } & \multicolumn{2}{|c|}{ DS3 } & \multicolumn{4}{|c|}{ DS4 } \\
\hline & & R2R & R2Rm & R2Rd & R2R & R2Rm R2Rd & $\overline{R 2 R}$ & R2Rm & R2Rd & R2R & R2Rm & R2Rd \\
\hline \multirow[t]{4}{*}{3} & 1 & 0.17 & 0.17 & \multirow{4}{*}{0.15} & 0.05 & 0.09 & 0.17 & 0.20 & \multirow{4}{*}{0.31} & 0.19 & 0.22 & \multirow{4}{*}{0.30} \\
\hline & 2 & 0.14 & 0.17 & & 0.05 & 0.11 & 0.21 & 0.21 & & 0.27 & 0.27 & \\
\hline & 3 & 0.14 & 0.17 & & 0.05 & 0.09 & 0.26 & 0.26 & & 0.26 & 0.27 & \\
\hline & 4 & 0.15 & 0.14 & & 0.05 & 0.11 & 0.24 & 0.27 & & 0.23 & 0.27 & \\
\hline \multirow[t]{4}{*}{6} & 1 & 0.11 & 0.13 & \multirow{4}{*}{0.11} & 0.08 & 0.13 & 0.05 & 0.11 & \multirow{4}{*}{0.43} & 0.13 & 0.14 & \multirow{4}{*}{0.19} \\
\hline & 2 & 0.04 & 0.11 & & 0.08 & 0.14 & 0.27 & 0.29 & & 0.09 & 0.10 & \\
\hline & 3 & 0.04 & 0.11 & & 0.08 & 0.14 & 0.10 & 0.11 & & 0.15 & 0.15 & \\
\hline & 4 & 0.04 & 0.06 & & 0.08 & 0.08 & 0.07 & 0.08 & & 0.06 & 0.06 & \\
\hline
\end{tabular}

460 Table 7. Materials vs structural details: effects on the DS3 pushover-based fragility median [g].

\begin{tabular}{|c|c|c|c|c|c|c|c|c|c|c|c|c|c|}
\hline \multirow[b]{2}{*}{ Storeys } & \multirow{2}{*}{ Detail } & \multicolumn{3}{|c|}{ DS1 } & \multicolumn{3}{|c|}{ DS2 } & \multicolumn{3}{|c|}{ DS3 } & \multicolumn{3}{|c|}{ DS4 } \\
\hline & & R2R & R2Rm & R2Rd & R2R & R2Rm & R2Rd & R2R & R2Rm & R2Rd & R2R & R2Rm & R2Rd \\
\hline 3 & & 0.14 & 0.14 & & 0.37 & 0.37 & & 0.52 & 0.52 & & 0.62 & 0.62 & \\
\hline & & 0.15 & 0.15 & & 0.37 & 0.36 & & 0.67 & 0.65 & & 0.77 & 0.75 & \\
\hline & & 0.15 & 0.15 & 0.15 & 0.37 & 0.36 & 0.31 & 0.79 & 0.79 & 0.69 & 0.87 & 0.87 & 0.80 \\
\hline & & 0.16 & 0.16 & & 0.37 & 0.36 & & 0.87 & 0.85 & & 0.99 & 0.96 & \\
\hline 6 & & 0.09 & 0.09 & & 0.19 & 0.18 & & 0.33 & 0.33 & & 0.60 & 0.65 & \\
\hline & & 0.11 & 0.11 & 011 & 0.19 & 0.19 & & 0.57 & 0.59 & & 0.73 & 0.73 & \\
\hline & & 0.11 & 0.11 & 0.11 & 0.19 & 0.19 & 0.19 & 0.72 & 0.72 & 0.67 & 0.74 & 0.75 & 0.75 \\
\hline & 4 & 0.11 & 0.11 & & 0.20 & 0.20 & & 0.78 & 0.78 & & 0.80 & 0.80 & \\
\hline
\end{tabular}


462 This paper investigated the relative effect of material uncertainties and joint structural details on the seismic fragility estimation 463 of existing RC frames. The variables for this study are selected according to the typical information obtained from in-situ 464 testing, which are the cylindrical compressive strength of concrete, the yield steel stress and the typology of structural details 465 in joint panels. Different Italian design codes ranging from 1939 to 2008 are selected to define five building classes, also 466 proposing a tentative mapping to international codes (New Zealand, USA). Each class is characterised by different structural

details, with more emphasis on exterior joint panels. For each class, two geometrical configurations are chosen: three- and sixstorey frames with three bays. For each of these ten configurations, random variations of material properties are sampled according to a nine-factorial design of experiment. Fragility curves are defined for each sampled frame, using numerical pushover analysis and the analytical method SLaMA, both coupled with the capacity spectrum method and using natural ground motion records. Such methods are validated by comparison with refined non-linear time-history analyses (NLTHA). The logarithmic standard deviation of the fragility curves is the selected proxy to quantify epistemic uncertainty.

The results of this study indicate that the logarithmic standard deviation of the fragility curves is significantly more sensitive to the structural details adopted in joint panels rather than to the properties of the materials. The effect of structural details is negligible for damage states defined by first cracking or yielding of the RC members, since the essentially-elastic behaviour of RC frames is practically independent from the details. The effect of structural details increases with the severity of the damage state, and it is significant for the life-safety and near collapse damage states. This result is deemed to be worthy of attention, since these damage states are related to the primary goal of seismic provisions in building codes; i.e. to protect life by avoiding collapses.

Effective shear-transfer mechanisms for interior joint panels can activate due to the confining effect of the adjacent beams, and their capacity is less affected by structural details. On the other hand, shear transfer in exterior joints relies on the bond of the beam longitudinal bars bent inside the joint itself. Therefore, exterior joints are particularly sensitive to this structural detail and this greatly affects fragility estimates. It is reasonable to assume that, within a single RC frame, structural details are similar for each exterior joint. Therefore, cover removal for one of those could potentially eliminate this particular uncertainty. 
For this reason, as a practical action, it is deemed that good practice for the in-situ testing of RC frames should incentivise and recommend the cover removal of at least one exterior joint panel, regardless of the required target "level of knowledge" of the existing structure.

\section{DATA AVAILABILITY STATEMENT}

Some or all data, models, or code that support the findings of this study are available from the corresponding author on request.

\section{ACKNOWLEDGEMENTS}

This study has received funding from the European Union's Horizon 2020 research and innovation programme under grant agreement No. 843794. (Marie Skłodowska-Curie Research Grants Scheme MSCA-IF-2018: MULTIRES, MULTI-level framework to enhance seismic RESilience of RC buildings). Dr Karim Tarbali is gratefully acknowledged for providing the candidate ground motions for this study.

\section{REFERENCES}

ACI Committee 318 (1971) Building Code Requirements for Structural Concrete (ACI 318-71), American Concrete Institute ACI Committee 318 (1956) Building Code Requirements for Structural Concrete (ACI 318-56), American Concrete Institute American Society of Civil Engineers (ASCE) (2017) Seismic evaluation and retrofit of existing buildings (41-17). American Society of Civil Engineer and Structural Engineering Institute, Reston, Virginia, USA

Ancheta TD, Darragh RB, Stewart JP, et al (2014) NGA-West2 database. Earthq Spectra 30:989-1005

Baker JW (2015) Efficient analytical fragility function fitting using dynamic structural analysis. Earthq Spectra 31:579-599. doi: 10.1193/021113EQS025M

Baker JW, Cornell CA (2006) Spectral shape, epsilon and record selection. Earthq Eng Struct Dyn 35:1077-1095. doi: $10.1002 /$ eqe. 571

Berry MP, Eberhard MO (2005) Practical Performance Model for Bar Buckling. J Struct Eng 131:1060-1070

Bradley BA (2013) A critical examination of seismic response uncertainty analysis in earthquake engineering. Earthq Eng Struct Dyn 42:1717-1729. doi: 10.1002/eqe

Bradley BA (2010) A generalized conditional intensity measure approach and holistic ground-motion selection. Earthq Eng Struct Dyn 39:1321-1342. doi: 10.1002/eqe.995

Carr AJ (2016) RUAUMOKO2D - The Maori God of Volcanoes and Earthquakes. Inelastic Analysis Finite Element program. Christchurch, New Zealand 
Celarec D, Ricci P (2012) The sensitivity of seismic response parameters to the uncertain modelling variables of masonryinfilled reinforced concrete frames. Eng Struct 35:165-177

Celarec D, Ricci P, Dolšek M (2012) The sensitivity of seismic response parameters to the uncertain modelling variables of masonry-infilled reinforced concrete frames. Eng Struct 35:165-177. doi: 10.1016/j.engstruct.2011.11.007

Celik OC, Ellingwood BR (2010) Seismic fragilities for non-ductile reinforced concrete frames - Role of aleatoric and epistemic uncertainties. Struct Saf 32:1-12. doi: 10.1016/j.strusafe.2009.04.003

Consiglio dei Ministri (1939) Regio Decreto Legge n. 2229 del 16/11/1939. G.U. n.92 del 18/04/1940.

Consiglio dei Ministri (1978) Decreto Ministeriale 3 ottobre 1978: Criteri generali per la verifica della sicurezza delle costruzioni e dei carichi e sovraccarichi

Consiglio dei Ministri (1976) Legge n. 176 del 26/04/1976. Norme per l'istruzione del servizio sismico e disposizioni inerenti ai movimenti sismici del 1971, del Novembre e Dicembre 1972, del Dicembre 1974 e del Gennaio 1975, in comuni della provincia di Perugia.

Consiglio dei Ministri (1996) Decreto Ministeriale 9/01/1996. Norme tecniche per il calcolo, l' esecuzione e il collaudo delle strutture in cemento armato normale e precompresso e per le strutture metalliche, supplemento ordinario alla G.U. n. 29 del 05/02/1996.

Consiglio dei Ministri (1997) Circolare del Ministero dei Lavori Pubblici n. 65 del 10/4/1997. Istruzioni per l'applicazione delle "Norme tecniche per le costruzioni in zone sismiche" di cui al Decreto Ministeriale 16 gennaio 1996. G.U. n. 97 del 28/4/1997 (in Italian)

Consiglio dei Ministri (2003) Ordinanza del Presidente del Consiglio dei ministri (OPCM) 20 marzo 2003, n. 3274. Primi elementi in materia di criteri generali per la classificazione sismica del territorio nazionale e di normative tecniche per le costruzioni in zona sismica.

Consiglio dei Ministri (2008) DM 14 gennaio 2008 in materia di “norme tecniche per le costruzioni”. Gazzetta ufficiale n.29 del 4 febbraio 2008, Supplemento ordinario n.30. Minist delle Infrastrutture e dei Trasp Ist Poligr e Zecca dello stato

Cristofaro MT, Stefano M De, Pucinotti R, Tanganelli M (2014) Caratteristiche meccaniche del calcestruzzo in situ (in Italian). In: $15^{\circ}$ Congresso AIPnD Biennale PnD-MD. Trieste, Italy

Crowley H, Despotaki V, Rodrigues D, et al (2020) Exposure model for European seismic risk assessment. Earthq Spectra. doi: $10.1177 / 8755293020919429$

De Luca F, Woods GED, Galasso C, D'Ayala D (2018) RC infilled building performance against the evidence of the 2016 EEFIT Central Italy post-earthquake reconnaissance mission: empirical fragilities and comparison with the FAST method. Bull Earthq Eng. doi: 10.1007/s10518-017-0289-1

Dolšek M (2009) Incremental dynamic analysis with consideration of modeling uncertainties. Earthq Eng Struct Dyn 38:805825. doi: $10.1002 /$ eqe. 869

European Committee for Standardisation (CEN) (2005) Eurocode 8: Design of structures for earthquake resistance. Part 3: Strengthening and repair of buildings

Franchin P, Ragni L, Rota M, Zona A (2018) Modelling Uncertainties of Italian Code-Conforming Structures for the Purpose of Seismic Response Analysis. J Earthq Eng 22:1964-1989. doi: 10.1080/13632469.2018.1527262

Freeman SA (2004) Review of the Development of the Capacity Spectrum Method. ISET J Earthq Technol 41:1-13

Galasso C, Maddaloni G, Cosenza E (2014) Uncertainly Analysis of Flexural Overstrength for Capacity Design of RC Beams. J Struct Eng 140:04014037. doi: 10.1061/(asce)st.1943-541x.0001024 
Gentile R, Del Vecchio C, Pampanin S, et al (2019a) Refinement and Validation of the Simple Lateral Mechanism Analysis (SLaMA) Procedure for RC Frames. J Earthq Eng

Gentile R, Pampanin S, Raffaele D, Uva G (2019b) Non-linear analysis of RC masonry-infilled frames using the SLaMA method: part 1-mechanical interpretation of the infill/frame interaction and formulation of the procedure. Bull Earthq Eng 17:3283-3304. doi: 10.1007/s10518-019-00580-w

Gentile R, Pampanin S, Raffaele D, Uva G (2019c) Non-linear analysis of RC masonry-infilled frames using the SLaMA method: part 2-parametric analysis and validation of the procedure. Bull Earthq Eng 17:3305-3326. doi: 10.1007/s10518-019-00584-6

Gentile R, Pampanin S, Raffaele D, Uva G (2019d) Analytical seismic assessment of RC dual wall/frame systems using SLaMA: Proposal and validation. Eng Struct 188:493-505. doi: 10.1016/j.engstruct.2019.03.029

Giardini D, Wössner J, Danciu L (2014) Mapping Europe's seismic hazard. Eos (Washington DC) 95:261-262. doi: 10.1002/2014EO290001

Gokkaya BU, Baker JW, Deierlein GG (2016) Quantifying the impacts of modeling uncertainties on the seismic drift demands and collapse risk of buildings with implications on seismic design checks. Earthq Eng Struct Dyn 45:1661-1683. doi: $10.1002 /$ eqe. 2740

Iervolino I, Galasso C, Cosenza E (2010) REXEL: Computer aided record selection for code-based seismic structural analysis. Bull Earthq Eng 8:339-362. doi: 10.1007/s10518-009-9146-1

Jalayer F, Cornell CA (2009) Alternative non-linear demand estimation methods for probability-based seismic assessments. Earthq Eng Struct Dyn 38:951-972. doi: 10.1002/eqe.876

Jalayer F, Iervolino I, Manfredi G (2010) Structural modeling uncertainties and their influence on seismic assessment of existing RC structures. Struct Saf 32:220-228

King DJ, Priestley MJN, Park R (1986) Computer programs for concrete column design, Research Report 86/12. Department of Civil Engineering

Kosič M, Dolšek M, Fajfar P (2012) Dispersions for the pushover-based risk assessment of reinforced concrete frames and cantilever walls Mirko. Earthq Eng Struct Dyn 45:2163-2183. doi: 10.1002/eqe.2753

Kowalsky MJ, Priestley MJN (2000) Improved analytical model for shear strength of circular reinforced concrete columns in seismic regions. ACI Struct J 97:388-396

Kwon OS, Elnashai A (2006) The effect of material and ground motion uncertainty on the seismic vulnerability curves of RC structure. Eng Struct 28:289-303. doi: 10.1016/j.engstruct.2005.07.010

Liel AB, Haselton CB, Deierlein GG, Baker JW (2009) Incorporating modeling uncertainties in the assessment of seismic collapse risk of buildings. Struct Saf 31:197-211. doi: 10.1016/j.strusafe.2008.06.002

Lin T, Haselton CB, Baker JW (2013) Conditional spectrum-based ground motion selection. Part I: Hazard consistency for risk-based assessments. Earthq Eng Struct Dyn 42:1847-1865. doi: 10.1002/eqe.2301

Magenes G, Pampanin S (2004) Seismic response of gravity-load design frames with masonry infills. In: 13th World Conference on Earthquake Engineering. Vancouver, B.C., Canada

Mander JB, Priestley MJN, Park R (1988) Theoretical stress strain model for confined concrete. J. Struct. Eng. 114:1804-1826

Manfredi G, Masi A, Pinho R, Verderame GM (2011) Valutazione degli edifici esistenti in Cemento Armato. Pavia, Italy

MOW1968 (1968) Code of Practice, Design of Public Buildings. Ministry of Works

New Zealand Society for Earthquake Engineering (NZSEE) (2017) The seismic assessment of existing buildings - technical 
guidelines for engineering assessments. Wellington, New Zealand

591

O’Reilly GJ, Sullivan TJ (2018) Quantification of modelling uncertainty in existing Italian RC frames. Earthq Eng Struct Dyn 47:1054-1074. doi: 10.1002/eqe.3005

Pampanin S (2017) Towards the practical implementation of performance-based assessment and retrofit strategies for RC buildings: challenges and solutions. In: SMAR2017- Fourth conference on Smart Monitoring, Assessment and Rehabilitation of Structures. 13-15 March 2017. Zurich, Switzerland

Pampanin S, Magenes G, Carr A (2003) Modeling of shear hinge mechanism in poorly detailed R.C beam-column joints. In: Concrete Structures in Seismic Regions: fib 2003 Symposium. Athens, Greece

Priestley M (1997) Displacement-based seismic assessment of reinforced concrete buildings. J Earthq Eng 1:157-192

Priestley MJN, Calvi GM, Kowalsky MJ (2007) Direct displacement-based seismic design of structures. IUSS Press, Pavia, Italy

Priestley MJN, Park R (1987) Strength and ductility of concrete bridge columns under seismic loading. ACI Struct J 84:6176

Ricci P, Manfredi V, Noto F, et al (2018) Modeling and Seismic Response Analysis of Italian Code-Conforming Reinforced Concrete Buildings. J Earthq Eng 22:105-139. doi: 10.1080/13632469.2018.1527733

Saiidi M, Sozen M (1979) Simple and complex models for nonlinear seismic response of reinforced concrete structures. Urbana, Illinois, USA

Santarella L (1977) Prontuario del cemento armato (in Italian). Hoepli, Milano, Italy

Standards association of New Zealand (1976) Code of practice for general structural design and design loading for buildings

Tarbali K, Bradley BA, Baker JW (2019) Ground motion selection in the near-fault region considering directivity-induced pulse effects. Earthq Spectra 35:759-786. doi: 10.1193/102517EQS223M

Verderame GM, Manfredi G, Frunzio G (2001) Le proprietà meccaniche dei calcestruzzi impiegati nelle strutture in c.a. realizzate negli anni ' 60 (in Italian). In: Proceedings of the 10th Conference on "Earthquake Engineering in Italy"

Verderame GM, Ricci P, Esposito M, Sansiviero FC (2011) Le caratteristiche meccaniche degli acciai impiegati nelle strutture in c.a. realizzate dal 1950 AL 1980 (in Italian). In: Associazione Italiana Calcestruzzo Armato e Precompresso (AICAP)

Wight J, Parra-Montesinos G (2012) Historical development of design recommendations for RC beam-to-column connections. In: ACI Spring 2012 Convention

Yu X, Lu D, Li B (2016) Estimating uncertainty in limit state capacities for reinforced concrete frame structures through pushover analysis. Earthq Struct 10:141-161. doi: 10.12989/eas.2016.10.1.141 